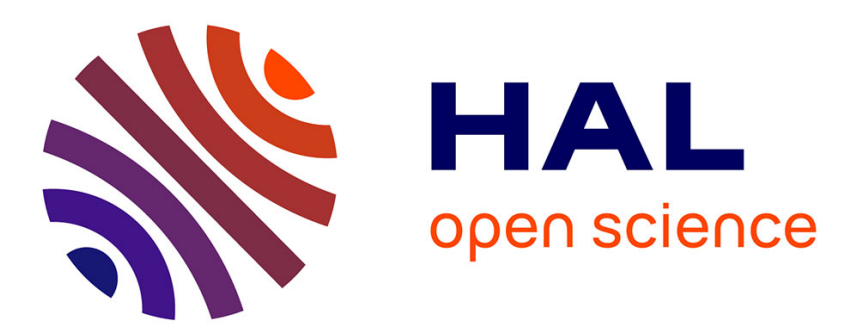

\title{
Effective medium modeling of diagenesis impact on the petroacoustic properties of carbonate rocks
}

Mathilde Adelinet, Jean-François Barthélémy, Elisabeth Bemer, Youri Hamon

\section{To cite this version:}

Mathilde Adelinet, Jean-François Barthélémy, Elisabeth Bemer, Youri Hamon. Effective medium modeling of diagenesis impact on the petroacoustic properties of carbonate rocks. Geophysics, 2019, 84 (4), pp.WA43-WA57. 10.1190/geo2018-0559.1 · hal-02101736

\section{HAL Id: hal-02101736 \\ https://hal.science/hal-02101736}

Submitted on 17 Sep 2019

HAL is a multi-disciplinary open access archive for the deposit and dissemination of scientific research documents, whether they are published or not. The documents may come from teaching and research institutions in France or abroad, or from public or private research centers.
L'archive ouverte pluridisciplinaire HAL, est destinée au dépôt et à la diffusion de documents scientifiques de niveau recherche, publiés ou non, émanant des établissements d'enseignement et de recherche français ou étrangers, des laboratoires publics ou privés. 
archives-ouvertes

\title{
Effective medium modeling of diagenesis impact on the petroacoustic properties of carbonate rocks
}

\author{
Mathilde Adelinet, Jean-François Barthélémy, Elisabeth Bemer, Youri Hamon
}

\section{To cite this version:}

Mathilde Adelinet, Jean-François Barthélémy, Elisabeth Bemer, Youri Hamon. Effective medium modeling of diagenesis impact on the petroacoustic properties of carbonate rocks. Geophysics, Society of Exploration Geophysicists, 2019, 84 (4), pp.WA43-WA57. 10.1190/geo2018-0559.1 . hal-02101736

\section{HAL Id: hal-02101736 \\ https://hal.archives-ouvertes.fr/hal-02101736}

Submitted on 17 Sep 2019

HAL is a multi-disciplinary open access archive for the deposit and dissemination of scientific research documents, whether they are published or not. The documents may come from teaching and research institutions in France or abroad, or from public or private research centers.
L'archive ouverte pluridisciplinaire HAL, est destinée au dépôt et à la diffusion de documents scientifiques de niveau recherche, publiés ou non, émanant des établissements d'enseignement et de recherche français ou étrangers, des laboratoires publics ou privés. 


\section{EFFECTIVE MEDIUM MODELING OF DIAGENESIS IMPACT ON THE}

PETROACOUSTIC PROPERTIES OF CARBONATE RCCKS

Mathilde Adelinet, Jean-François Barthélémy, Elisabeth Bemer, Youri Hamon

\section{ABSTRACT}

Carbonate formations are heterogeneous and their velocity - porosity relationships are mainly controlled by microstructural parameters. As diagenesis is responsible for important changes in the microstructure of carbonate rocks, we propose here to extend the classic effective medium approach to model the impact of diagenesis on carbonate elastic properties through a step by step effective medium modeling. Two different carbonate formations are considered. The first key step is the characterization of the diagenesis which affected the studied carbonate series. An effective medium model integrating all the geological information accessible from thin section analysis is then built. The evolution of the microstructural parameters during diagenesis is thoroughly constrained based on an extensive experimental dataset, including XRD analysis, various porosimetry techniques and ultrasonic velocities measurements. Finally, direct calculations with the model provide elastic wave velocities representative of the different diagenetic stages. An extrapolation to permeability evolution is also introduced. This approach allows the identification of the acoustic signature of specific diagenetic events, such as dolomitization, dissolution or cementation, and the assessment of their impact on the flow properties of carbonate formations. 
Geophysics

\section{INTRODUCTION}

Carbonate formations represent major targets for exploration and development of hydrocarbon reservoirs. Giant discoveries in offshore Brazil or Levant Basin for instance are driving new research avenues. In a more environmental context, carbonates are considered as key indicators of paleoclimates (Eiler et al., 2011). Indeed the various processes leading to their accumulation reflect the complex interplay between water chemistry, biotic productivity, sediment availability and geodynamic context. This is especially true for continental carbonates, thus adding hydrologic constrains (Kelts, 1990). Due to their various depositional modes, carbonates are characterized by wide ranges of primary fabrics and associated pore types. Afterwards, these fabrics are affected by different diagenetic processes which can either create or occlude porosity (Heydari, 2003; Lambert et al., 2006; Casteleyn et al., 2010, 2011; Makhloufi et al., 2013; Neveux et al., 2014; Carpentier et al., 2015; Clark and Vanorio, 2016; Nader et al., 2016). Besides, carbonate rocks show very specific mechanical compaction processes such as crystal plasticity and cataclasis (Vajdova et al, 2004; Baud et al., 2009; Nicolas et al., 2016), which further complicates the resulting microstructures.

Porosity, fabrics and pore types being the main control factors of elastic velocity in carbonate rocks (Eberli et al., 2003; Baechle et al., 2008; Verwer et al., 2008), it seems natural to seek to link elastic properties and diagenesis. However, only a few studies tackle the key issue of relating sedimentological and diagenetic features to physical properties measured at the sample scale and extrapolating the obtained results at the formation scale to derive global evolution laws (Brigaud, 2010; Regnet et al., 2015a, 2015b; Matonti et al., 2015, 2016). Numerous acoustic 
Geophysics

experimental data have been acquired on carbonate rocks showing a wide range of variation and indicating no clear velocity - porosity trends (Adam et al., 2006; Rasoiofosaon and Zinszner, 2003; Rasolofosaon et al., 2008; Bemer et al., 2017). That is why modeling approaches have been developed to explain the different elastic behavior observed on carbonates (Dvorkin et al., 1995; Adam et al., 2006; Dou et al., 2011; Ba et al., 2013; Fournier et al., 2018; Regnet et al., 2018). One of the most famous is the model developed by Xu and Payne (2009) which is an extension of the model of Xu and White (1996) proposed for clastic rocks. in this model, the authors assume that interparticle pores represent the most common pore type in carbonate rocks and therefore provide a reference porosity - velocity trend. Reference pores are modeled by ellipsoids with an aspect ratio equal to 0.15 . Mixed pore types are then considered by added either stiff pores (ellipsnids with an aspect ratio of 0.8 ) or cracks (ellipsoids with an aspect ratio of 0.02 ) to the reference pores. The aspect ratio of 0.15 representing the reference pores appears to be flatter than what is usually observed on thin sections for interparticle pores (Lonoy, 2006). Using this model or other approaches only based on pore aspect ratios (e.g. Fournier et al., 2018), lower experimental velocity data can only be explained through the presence of cracks within the studied rocks. Yet, such features are scarcely observed on thin sections for carbonates contrary to other rocks, for instance volcanic ones, where cracks lead to a specific mechanical behavior (Adelinet et al., 2010; 2013). Moreover, for some carbonate rocks, velocities remain low even if the confining pressure is increased enough to close the majority of cracks and microdefects.

We thus propose a different approach to model the specific elastic behavior shown by carbonate rocks where we introduce an interface stiffness around the main solid grains, which can be dolomite or calcite in our case. By decoupling the elastic properties of the grain and its 
Geophysics

interiace, we add an additional compliance at the macroscale intended to represent the mechanical response of grain contacts (Rasolofosaon and Zinszner, 2003). This is in agreement with observed sedimentological features (Brigaud et al., 2010; Regnet et al., 2015a). We then use the effective medium modeling as a tool to provide elastic velocities at different diagenesis stages. This study is based on experimental results derived from a specific characterization workflow designeci to provide a comprehensive dataset including both input and constraining data for effective medium modeling (Bemer et al., 2018).

\section{METHODS}

\section{Experimental approach}

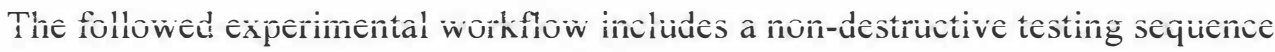
performed on the main sample and a series of microstructure analyses performed on subsamples. The successive non-destructive characterization steps are: petroacoustic testing, porosity measurement, NMR analysis on the brine-saturated sample and brine permeability measurement. The main sample is then cut into several subsamples to obtain a vertical thin section, powder for $\mathrm{XRD}$ analysis and small parts for mercury injection and possibly microscanner imaging. This last analysis being costly, it is not performed on the whole sample set.

The key steps of the workflow are the petroacoustic testing performed on the main samples and the petrographic characterization performed on the vertical thin sections. The other measurements are more standard and their contribution arises from their consistent combination.

\section{Petrographic characterization}


One thin section per sample (cut along the axis of the oriented samples) has been analyzed for faciologic and diagenetic purposes (texture, fabric, grain types, pore types, mineralogy, cementation or dissolution features...). All thin sections are impregnated with blue epoxy to identify the pore space) and stained with alizarin red-S to differentiate carbonate minerals: (calcite is stained, while dolomite remains unstained; Dickson, 1966) and potassium ferricyanid for distribution of ferrous iron.

Pre-microscopic observations are carried out under reflected and transmitted light with a binocular microscope (Nikon SMZ 800) to have a large scale view of the samples and characterize their general texture and porosity distribution. Petrographic observations are then performed with a Nikon Eclipse LV100 POL microscope.

The thin section analysis provides qualitative structural information on the organization of the different microstructural components (matrix, cement, pores). The sedimentary texture are described using the classification of Dunham (1962), whereas the dolomite fabrics are described using the classification of Sibley and Gregg (1987). The porosity is described following the classification of Choquette and Pray (1970) and Lonoy (2006).

Image analysis on scanned thin sections has moreover been performed to provide a surfacic estimation of the porosity and the mineral content by extracting the different colors through threshold methods. The image analysis is performed with JMicroVision, which is a freeware software designed to describe, measure, quantify and classify components of all kinds of images and especially developed to analyze high definition images of rock thin sections (http://www.jmicrovision.com/index.htm). 
Geophysics

Peiroacoustic testing

The petroacoustic ceil has been designed to perform velocity measurements under an isotropic confining pressure (up to $70 \mathrm{MPa}$ ). The sample is set in an impermeable Viton $®$ jacket to prevent any communication between the pore fluid and the confining fluid. The tests can thus be performed at various differentiai pressures (i.e. difference between the confining pressure and the pore pressure), and with various saturating fluids. All the tests have been carried out at a differential pressure representative of in situ conditions.

The upper and lower heads of the cell include a double P and S transducer (half-moon ceramic, central frequency of $500 \mathrm{kHz}$ ). The first specificity of our approach is to analyze the ultrasonic signals using the phase spectral ratio method, which gives the phase velocity (Rasolofosaon and Zinszner, 2003). This method consists in applying a Fourier transform to the recorded signai and to compare it, in the frequency domain, with a reference signal recorded in a homogeneous medium of perfectly known velocity (in this case an aluminum sample). Carbonate heterogeneity induces scattering effects usually referred to as "path dispersion" (Cadoret et al., 1995). Contrary to the first break picking which leads to overestimated acoustic velocities, the computation of the phase velocity allows a minimization of the heterogeneity effect (Rasolofosaon et al., 2008). The error on phase velocity measurements can be considered as less than $2 \%$, with a corresponding error on $V_{P} / V_{S}$ ratio less than $4 \%$ (Bemer et al., 2018).

The second specificity is to follow the fluid substitution method developed by Rasolofosaon and Zinszner (2003). This approach consists in subsequently measuring the acoustic velocities for various saturating liquids of different bulk modulus, the current saturating fluid being replaced with a miscible one to ensure successive fully saturated states. The 
substitution sequence is the following: brine $(25 \mathrm{~g} / \mathrm{l} \mathrm{NaCl})$, ethylene glycol, methanol, ethanol, heptane, ethanol, brine $(25 \mathrm{~g} / \mathrm{l} \mathrm{NaCl})$. The key contribution of fluid substitution tests is to allow a direct checking of the validity of Biot-Gassmann's equation without referring to less-controlled dry measurements and without any assumption on the solid matrix bulk modulus (Bemer et al., 2018). The obtained results moreover permit the direct identification of any weakening or dispersion effects.

\section{Combined microstructure characterization}

The construction of a relevant microstructure model requires consistent information on the mineral content and the porous phase, especially the proportion of microporosity and macronorosity. The location of the microporosity has also to be specified. The experimental workflow systematically includes X-Ray Diffraction (XRD) analysis to identify the mineral phases and determine their volume fractions, and two different technics of pore-size characterization: Nuclear Magnetic Resonance (NMR) and Mercury Injection Capillary Pressure (MICP). These methods are detailed in our companion paper (Bemer et al., 2018). We focus here on the key issues underlying their interpretation.

NMR and MICP explore different physical parameters and sample sizes: the NMR $T_{2}$ relaxation time is related to the pore volume over surface ratio and the $T_{2}$ distribution is obtained for the whole sample, while MICP gives information on the pore throat size distribution for a small part of the sample. The NMR analysis can be perturbed by pore coupling effects induced by the mixing of molecules from nearby compartments through diffusion process. When no pore coupling is observed, a comparative study between NMR and MICP data obtained on carefully selected carbonate samples of various origins has shown that a cut-off of $200 \mathrm{~ms}$ in the NMR $T_{2}$ 
distribution could be used to separate the microporosity from the macroporosity, in accordance with: a pore throat diameter cut-off of $2 \mu \mathrm{m}$ for MICP distributions (Vincent et al., 2011).

Microscanner imaging has been performed to provide additional information on the repartition of micropores within the samples. Subsamples of $8-\mathrm{mm}$. diameter are imaged for two saturation states: dry and saturated by a $40 \mathrm{~g} / \mathrm{K} \mathrm{K}$-brine. Image subtraction can then be carried out to identify the macropores and the microporous areas and derive the macroporosity and microporosity volume fractions. The threshold between macroporosity and microporosity is then associated to the image resolution which is equal to $8 \mu \mathrm{m}$ for the imaged 8 -mm subsamples. The information provided by microscanner imaging is the more physically consistent for effective medium modeling. It is however not available for all the samples and obtained on a smaller volume than the NMR data.

The information derived from the NMR, MICP and microscanner analyses are finally integrated to derive consistent fractions of microporosity and macroporosity for effective medium modeling.

\section{Effective medium modeling}

Theory

For sedimentary rocks such as sandstones, it is usually easy to derive a relationship between elastic properties and microstructure description. However, due to their complex microstructures, carbonate rocks do not appear to follow any simple or direct specific relationship. The challenging issue is then to derive consistent elastic properties for carbonate rocks from microstructure information. The effective medium theory offers a neat way to achieve 
this objective. Indeed, it relies on physica! models that describe within a Representative Elementary Volume (REV) the macroscopic properties of a medium based on microstructural characteristics. Such a theory can be used through a direct way, i.e. the elastic properties of the rock are calculated from an exhaustive description of the microstructure, or through an inverse approach, i.e. some microstructure features are derived from macroscopic properties such as velocities. The effective medium modeling used in this study is a homogenization approach relying on Eshelby's inclusion theory (Eshelby, 1957). The conceptual framework of the theory consists in considering an ellipsoidal inclusion embedded within an infinite medium and the disruption of the strain field in the medium due to this inclusion. As different inclusions are present within a rock, for instance grains, pores or cracks, we have to use a homogenization scheme to derive the macroscopic elastic properties at the REV scale. Different schemes can be found in the literature. As carbonate rocks have complex microstructures and relatively high porosities, we choose to use the self-consistent approach. In this scheme, an inclusion is embedded within a medium which has the elastic properties of the effective medium. There are no limits in porosity and it is well-adapted for unorganized mediums such as carbonate rocks. Table 3 reports the elastic moduli allocated to the pure mineral phases present in the studied samples.

As elastic velocities measured on carbonate samples are often lower than what would be expected from simple modeling (Eberli et al., 2003; Regnet et al., 2018), several authors have introduce some cracks into the theoretical microstructure in order to better reproduce the measured values (Xu and Payne, 2009; Zhao et al., 2013; Fournier et al., 2018). However, cracks are rarely observed in geological thin sections. That is why we choose another approach to model the specific behavior of carbonates. We introduce a compliant interface around the main 
Geophysics

carbonate grains intended to represent the mechanical response of grain contacts (Rasolofosaon: and Zinszner, 2003). in this approach, the grains have the mechanical properties of the considered mineralogical phase (calcite or dolomite in our case) but the grain interface may have different properties allowing a softer macroscopic behavior, and finally lower velocities than the ones modeled without this compiiant interface.

From a theoretical point of view, carbonate grains are modeled as rigid inclusions with a smooth interface (Barthéiémy, 2005). These inclusions differ from cohesive inclusions through: some mechanical discrepancies. First, the tangential component of the displacement field $\xi$ at the interface may be discontinuous but not the normal one, which prevents debonding or interpenetration of grains. Second, at the interface between the homogenized medium and the inclusion, the stress vector $\boldsymbol{\sigma} \cdot \boldsymbol{n}$ is purely normal:

$$
\begin{aligned}
& \llbracket \xi \rrbracket \cdot \boldsymbol{n}=0 \\
& \boldsymbol{\sigma} \cdot \boldsymbol{n}=\sigma_{n n} \boldsymbol{n}
\end{aligned}
$$

where $\boldsymbol{n}$ is the unit vector normal to the interface and $\sigma_{n n}$ is the normal component of the stress vector on the interface.

Contrary to pores, the strain field is null within the solid inclusions. However, if the inclusion is surrounded by a smooth interface, the displacement discontinuities contribute to the average of the strain field. The only constraint on the stress field is to ensure the continuity of the stress vector at the interface between the homogenized medium and the inclusion. Finally, we obtain a linear relationship between the stress vector at the interface and the displacement discontinuity: 
Geophysics

$$
\sigma \cdot n=\kappa \cdot \llbracket \xi \rrbracket \text { with } \kappa=\kappa^{n} n \otimes n+\kappa^{t}(1-n \otimes n)
$$

where $\kappa^{n}$ and $\kappa^{t}$ are the normal and tangential stiffness of the interface.

The normal and tangential stiffness of the interface cannot be determined experimentally and have to be calculated through the inversion of the measured ultrasonic velocities. As for any inverse problems, the objective is to minimize an objective function $J$ which is written as:

$$
J\left(\kappa^{n}, \kappa^{t}\right)=\frac{1}{2}\left\{1-\frac{\left[V_{P}^{\text {model }}\left(\kappa^{n}, \kappa^{t}\right)\right]^{2}}{\left[V_{P}^{\exp }\right]^{2}}\right\}^{2}+\frac{1}{2}\left\{1-\frac{\left[V_{S}^{\text {model }}\left(\kappa^{n}, \kappa^{t}\right)\right]^{2}}{\left[V_{S}^{\exp }\right]^{2}}\right\}^{2}
$$

where the subscripts ${ }^{\text {exp }}$ and ${ }^{\text {model }}$ stand respectively for experimental data and effective medium modeling results. The minimization of this objective function will determine the unknown microstructure parameters $\kappa^{n}$ and $\kappa^{t}$ yielding the modeled velocities closest to the experimental ones.

\section{Modeling workflow}

A modeling workflow has been defined to calculate the elastic properties evolution according to diagenesis based on effective medium models and the extensive experimental dataset available on the studied carbonate samples. Figure 1 summarizes the different steps of this workflow. First, image analysis on thin sections, XRD analysis and pore size information derived from MICP, NMR and microscanner images (when available) are used to describe the layout of the rock microstructure: types and volume fractions of grains, identification of the solid phase with an interface, volume of cement, types of porosity, volume fractions of macroporosity and microporosity, location of microporosity... Based on the defined microstructure model, we use the measured ultrasonic velocities to invert the mechanical properties of the introduced interface. 
As diagenetic events in carbonates are associated with aqueous fluid flows, the saturating fluid used in the effective medium modeling is brine whose elastic parameters are given in Table 5. Accordingly, the ultrasonic velocities considered here correspond to the brine-saturated measurements. The range of porosity covered by the samples from each family is sufficiently large to ensure a reasonable calibration of the interface parameters. At the end of this first step, the derived microstructural model is representative of samples having experienced all the diagenetic events.

The accurate diagenetic study performed on the thin sections is then used to individualize the different diagenetic events and translate them into a step-by-step evolution of the effective medium model. Finally, elastic properties are computed through the entire theoretical diagenetic path. To do so, we consider that the interface stiffness parameters determined through inverse analysis are representative of one specific mineral object (calcite or dolomite grains) and do not evolve during diagenesis, which is a very strong hypothesis.

The main unknown remains the time of the diagenetic events. We thus use an arbitrary temporal scale to represent the different diagenetic steps. We assume that all the samples are representative of the final stage of diagenesis and have thus experienced all the previous diagenetic steps identified in the paragenesis. They may however have been more or less impacted by the last diagenetic process. We thus use their different macroporosity and microporosity values to calibrate the evolution of the final diagenetic step. The evolutions during the previous diagenetic steps are then defined based on the constraints imposed by the final diagenetic step and additional assumptions on the initial stage based on our general knowledge on carbonate systems. 
Geophysics

\section{PETROGRAPHIC CHARACTERIZATION: DEFINITION OF PARAGENESIS}

\section{Family 1}

The five investigated samples roughly exhibit the same kind of texiture, whicin may be described as a thrombolytic one (Riding, 1991). The latter is composed of iarge scale coalescent "mesoclots" (up to $4 \mathrm{~mm}$ long and $2 \mathrm{~mm}$ wide) forming a bushy, dendritic frame, loosely packed. These mesoclots have a sweeping feather-like extinction and a calcitic mineralogy. Samples F112, F1-15, F1-17 and F1-21 are very similar and show the development of a dolomite cement (Figure 2A). This cement is however poorly represented in sample F1-13 (Figure 2B). Important cement-reduced growth framework porosity (as defined in Choquette and Pray, 1970) is observed and image analysis estimations range from $8 \%$ (sample F1-15) to $18 \%$ (sample F1-17), These observations could point to a direct covariance between dolomite cementation and porosity. The mineral contents and porosity estimated trough image analysis are reported in Table 1 .

Several diagenetic phases can be identified and are presented in Figure 3 according to their relative timing established through crosscutting relationships observed during petrographic analyses and described below. Note that the proposed paragenesis should be considered with caution as it is only based on the observation of a few samples.

Millimetric silica orbicules with an irregular morphology are first observed in some mesoclots and even sometimes around mesoclots. They are composed of amorphous quartz (Silica 1), formed of anhedral crystals with wavy borders. The size of the quartz crystals is variable and range from 200 to $500 \mu \mathrm{m}$. 
A cement phase consisted in a dog tooth, non ferroan calcite cement (Figure 2C, white arrow) is then observed. It occurs as a first generation of voids filling (lining the mesoclots) and clearly predates the dolomite cement (Figure 2C, black arrow). Crystal sizes range from 30 to $60 \mu \mathrm{m}$.

A few stylolites are observed in sample F1-21, but with no clear cross-cutting relationships between these structures and the other diagenetic phases. The dolomite cement may however have postdated the stylolitization, as the crystals are not affected by stylolites. Additional observations would be needed to precise this relative timing and the origin of the stylolitization.

Dolomitization occurs in varying proportions for all the studied samples as a dolomite cement in the porosity. It exhibits a planar-e texture (Sibley and Gregg, 1987; mainly euhedral crystals) with crystal sizes ranging from 100 to $250 \mu \mathrm{m}$ (Figure 2C and Figure 2D, black arrow). These crystals show a concentric zoning with a cloudy (sometimes brown) core and a limpid, clear rim (10 to $50 \mu \mathrm{m})$.

This last rim shows a very irregular periphery and has thus clearly been corroded, possibly pointing to a late alteration (dissolution) of the crystals. This dissolution phase has also affected the mesoclots and may have created a vuggy micro-porosity (selective dissolution; Figure 2E and Figure 2F, black arrow).

A phase of quartz cement (Silica 2) is observed in all the samples and particularly in samples F1-12 and F1-21. This cement is composed of anhedral to subeuhedral limpid crystals ranging from 50 to $400 \mu \mathrm{m}$ and showing a drusy to granular development (Figure 2G, black 
arrow). It is developed in the porosity and clearly engulfs the dolomite cement, therefore postdating it.

In sample F1-12, scarce gypsum cement is observed. It forms cloudy inclusion-rich crystals, displaying a tabular anhedral habitus (Figure $2 \mathrm{H}$, black arrow). It develops in the growth framework porosity, and engulfs dolomite crystals, thus postdating them (Figure $2 \mathrm{H}$, white arrow). The relative timing with the Silica 2 cement cannot be determined as no crosscutting relationships are observed.

\section{Family 2}

The six investigated samples are dolomitized bioclastic wackestone to packstone (Figure 4). When preserved, bioclasts correspond to debris of echinoderms, lamellibranch and rare benthic foraminifera. The matrix is pervasively but selectively dolomitized, as well as some bioclasts or intraclasts. Porosity estimations (2D image analysis) range from 0 to $5 \%$, and the pore space is mainly made of moldic macropores (associated to bioclast dissolution) and intercrystalline micropores (within the dolomitized matrix). The mineral contents and porosity estimated trough image analysis are reported in Table 1.

Several diagenetic phases can be identified and are presented in Figure 5 according to their relative timing established through crosscutting relationships observed during petrographic analyses and described below. As for Family 1, the proposed paragenesis should be considered with caution as it is only based on the observation of a few samples.

A syntaxial cement mainly distributed as overgrowths $(50 \mu \mathrm{m}$ to up to $1 \mathrm{~mm})$ around crinoid fragments (Figure 4A and Figure 4B, white arrow) is observed in all the samples. It is 
Geophysics

composed of̂ inclusion-rich crystals of slightly ferroan calcite, frequently showing cleavage twins.

A fabric-preserving replacement (inversion) of aragonitic allochems (mainly lamellibranchs) by a non-ferroan inclusion-rich calcite is observed. The neomorphic calcites are identified by tine presence of solici organic and/or inorganic inclusions that concentrated aiong the original sheli growth iines and are still visible in the replaced allochem (Figure 4A and Figure $4 \mathrm{C}$, black arrow). The replacement fabric is characterized by a mosaic of coarse (50 to $100 \mu \mathrm{m}$ ) polygonal inclusion-rich non-ferroan low-magnesian calcite (LMC) crystals, which either crosscuts the original fabric or develops following the host shell microstructures.

The observed moldic porosity probably results from the dissolution of aragonite and high-magnesian calcite, which was not previously inverted in low-magnesian calcite (Figure 4D).

Dolomitization occurs in all the studied samples either through replacement or cementation. The degree of dolomitization depends on the considered sample (Table 1). Dolomite replacement is characterized by a unimodal dolomicrosparite, with crystals ranging from 10 to $50 \mu \mathrm{m}$ (Figure 4E) and showing a cloudy core and a more limpid overgrowth. More rarely, dolomite cement is observed in moldic porosity. It exhibits a planar-e texture (mainly euhedral crystals) with crystal sizes ranging from 100 to $200 \mu \mathrm{m}$ (Figure 4F). Observation of dolomite having affected syntaxial cement (Figure 4B) or developed in moldic porosity suggests that the dolomitization process postdated these two phases. 
For sample F2-2, an additional calcite cement phase is observed in moldic or shelter porosity (Figure 4G, black ariow). It corresponds to a drusy pore-filling cement, composed of equant subhedral non-ferroan calcite crystals (100 to $300 \mu \mathrm{m}$ ).

Finally, gypsum cement is scarcely observed in samples F2-4 and F2-7. It forms cloudy inclusion-rich crystals, displaying a tabular to bladed anhedral habitus (Figure 4H, black arrow). It develops in moldic porosity, partiaily or totally filiing some molds.

\title{
EXPERIMENTAL CHARACTERIZATION: MICROSTRUCTURE INFORMATION AND
} PETROACOUSTIC PROPERTIES

\author{
The mineral phases identified through the interpretation of XRD signals are calcite, \\ dolomite and silicate (grouping quartz and a small fraction of feldspars). Table 2 gives for each \\ studied sample the mineral content deduced from XRD analysis. The results are consistent with \\ the thin section analysis (Table 1). F1 samples show significant contents of both calcite and \\ dolomite and the largest silicate content of the two sample sets. Except for sample F2-2, F2 \\ samples are predominantly dolomite samples, with small amounts of silicate. However, as no \\ quartz phase has been observed on thin sections, we do not considered a silicate phase in the \\ model describing Family 2.
}

The total porosity of the samples is deduced from the brine volume provided by the NMR analysis of the brine-saturated samples and their bulk volume (Table 3). Additional porosity measures are obtained from the difference between the brine-saturated and dry weights of the samples. The comparison of the two measures shows that residual brine remains within the sample after drying at $60^{\circ} \mathrm{C}$ (Bemer et al., 2018). Effective medium modeling considers all the 
saturated volume including even the less accessible pores and the consistent porosity values are thus the NMR ones.

As described in our companion paper (Bemer et al., 2018), the microporosity and macroporosity fractions reported in Table 3 have been determined from the combined information derived from NMR and MICP analyses and microscanner imaging. The vaiues selected for effective medium modeling correspond to the volume fractions deduced from the NMR $T_{2}$ distributions by applying a $200 \mathrm{~ms}$ threshold. A more reliable set of values deduced from microscanner imaging is also provided for sample F1-13 which exhibits pore coupling (Fleury and Soualem, 2009).

Figure 6.4 plots the P-wave and S-wave velocities measured on the brine-satiurated samples as a function of porosity. The corresponding values are reported in Table 4 . The measurements on F1 and F2 samples have been performed at differential pressures equal to respectively $25 \mathrm{MPa}$ and $20 \mathrm{MPa}$ and have not been impacted by weakening or dispersion phenomena (Bemer et al., 2018). For a given porosity, F2 samples show higher P-wave and Swave velocities than F1 samples. At the first order it is related with higher contents of dolomite in F2 samples. Dolomite having higher bulk and shear moduli than calcite (Table 2), velocities are usually higher in dolomitic rocks than in calcite ones. Figure $6 \mathrm{~B}$ represents the ultrasonic measurements in a rock physics template: $V_{P} / V_{S}$ ratio versus P-wave impedance $I_{P}=\rho V_{P}$. Except for sample $\mathrm{F} 1-17, \mathrm{~F} 1$ samples show higher $V_{P} / V_{S}$ ratio than $\mathrm{F} 2$ samples. Both families are clearly separated in the diagram implying that primary and secondary structures in these carbonates have an incidence on their geophysical response. 


\section{Family 1}

As described in the petrographic analysis, F1 samples exhibit large scale calcitic mesoclots and a calcite cement forming the global rock frame, a dolomite cement developed between the calcite mesoclots, a framework porosity and micropores located both within the dolomite cement and the calcite mesoclots (Figure 2). The various characterizations performed on F1 samples have not provided quantitative data on the distribution of the micropores between their two host phases. As the dissolution step identified in the paragenesis mainly concerned the dolomite cement, we allocate the totality of the microporosity to this phase. This assumption can naturally be discussed, but additional data from high resolution SEM would be required to go further.

The microstructure model proposed for Family 1 is described in Figure 7A. It is based on a double scale approach. At the last diagenetic stage, the macroscopic scale consists in spherical grains of calcite with a compliant interface, quasi-equant macropores, spherical grains of quartz and microporous grains of dolomite. The microscopic scale corresponds to the microporous 
Geophysics

grains which are composed of a dolomite matrix and quasi-equant micropores. The volume fractions of these different phases having been determined for each sample (Table 2 and Table 3), this final model is first used to assess the normal and tangential stiffness of the interface through inverse analysis of the measured brine-saturated velocities (Table 4).

Concerning the diagenetic evolution, we only take into account the events observed on all the investigated samples during the petrographic analysis (Figure 8A). The initial state corresponds to the end of the first diagenetic event identified in the petrographic analysis (Figure 3), i.e. the formation of the first phase of silica (Si. 1) and the development of the calcite cement. At the beginning of our diagenesis modeling, the rock is then composed of calcite grains with a compliant interface (representing the rock frame composed of calcite mesoclots and syntaxial cement), macropores and amorphous quartz. This first stage corresponds to the early induration by cementation. We assume a total initial porosity of $40 \%$ which is a classical value for carbonate muds (Eberli et al., 2003). A small volume fraction of $1 \%$ is taken for the Si. 1 phase.

Three main diagenetic events are then considered (Figure 8A). Firstly, dolomite cement precipitates into the macroporosity of the initial calcite framework (Stage 1: dolomitization). Then, newly dolomite grains are dissolved and become microporous (Stage 2: dissolution). During this stage, dolomite grains become the second effective medium model embedded within the first one composed of calcite grains, macropores and amorphous quartz. Finally, quartz cement precipitates into the residual macroporosity (Stage 3: cementation).

The corresponding evolutions of the total porosity, the macroporosity and the microporosity are represented in Figure 9. During stage 1, the total porosity decreases due to a reduction of the macroporosity associated to the increase in dolomite content (dolomite 
Geophysics

precipitation). During stage 2, the total porosity increases due to the creation of microporosity within the dolomite grains, while the macroporosity remains constant. Finally, during stage 3 , the total porosity decreases due to the precipitation of quartz into the residial macroporosity (the microporosity remains constant). The total porosity level at the end of stage 1 corresponds to the macroporosity level maintained during stage 2 before the beginning of quartz cementation in stage 3. Sample FI-2l is characterized by the highest values of total porosity and macroporosity together with a low quartz content. It has then been considered as representative of the end of stage 2 and its porosity values have been used to constrain the constant macroporosity level of stage 2 and the constant microporosity level of stage 3, respectively set to $15 \%$ and $6.5 \%$. The four other samples are then reported on the porosity evolution curves according to their total porosity and their fractions of macroporosity and microporosity (Figuire 9 ) and thus attributed a position on the arbitrary time scale. The two positions proposed for sample FI-13 correspond to the macroporosity and microporosity fractions derived from NMR (filled markers) and microscanner imaging (white markers).

All the model parameters are then known and we can use direct effective medium modeling to compute the evolution of elastic wave velocities during the diagenesis. The red curves in Figure 10A report the results obtained for Family 1 in a velocity - porosity diagram. The comparison with the measured velocities illustrates the quality of the calibration. Figure 10B presents the temporal evolution of the elastic velocities during diagenesis. Ultrasonic measurements have been reported on the velocity curves using the time calibration described above. The first diagenetic stage is associated with a sharp increase of elastic velocities, corresponding to the filling of macropores with dolomite crystals. Then the dissolution of dolomite grains leads to a slight decrease of velocities. Finally the quartz cementation increases 
once again the velocities. Experimental data fit well with the model curves. As sample F1-21, sample F1-17 seems to be representative of the beginning of stage 3, while samples F1-12 and F1-15 appear as more representative of the end of stage 3 . These observations are in accordance with their relative quartz contents. Sample F1-13 shows a very low quartz content, which would be contradictory with its positioning at the end of stage 3 as would have been implied by the macroporosity and microporosity fractions derived from NMR data impacted by pore coupling. The use of the values derived from microscanner imaging (white markers) results in a shifting towards early times more consistent with the low quartz content of sample F1-13. These results show that reliable assessment of the macroporosity and macroporosity fractions is of paramount importance.

\section{Family 2}

As described in the petrographic analysis, F2 samples are dolomitized bioclastic wackestone to packstone. The matrix is selectively dolomitized. Porosity is split into moldic macropores and intercrystalline micropores within the dolomitized matrix. The microstructure model proposed for Family 2 is once again a double scale effective medium model (Figure 7B). At the last diagenetic stage, the macroscopic scale consists in a calcite matrix, representing both non-dolomitized grains of neomorphic calcite (resulting from the HMC/aragonite inversion diagenetic phase) and syntaxial cement, quasi equant macropores (aspect ratio equal to 0.8 ) and microporous grains of dolomite with a compliant interface. The microscopic scale corresponds to the dolomite microporous grains composed of a dolomite matrix and quasi equant micropores (aspect ratio equal to 0.8 ). As for Family 1, this final model is used to assess the normal and 
Geophysics

tangential stiffness of the interface through inverse analysis of the measured brine-saturated velocities.

In terms of diagenesis, the petrographic analysis has identified different main diagenetic phases (Figure 5). Besides, NMR measurements clearly show that the replacing dolomite is microporous; we have thus added another possible diagenetic step corresponding to the dissolution of dolomite (which could have occurred at the same time than the replacement of calcite by dolomite). Our diagenesis modeling begins with a tight carbonate rock whose porosity has been occluded by the development of syntaxial cement and which has thus already experienced some diagenetic processes after sedimentation. Three diagenetic phases which create porosity into the rock are then considered (Figure $8 \mathrm{~B}$ ). Firstly, macroporosity is created into the calcite matrix (Stage 1: dissolution). Then part of the initial calcite grains are replaced by dolomite grains with no change in porosity (Stage 2: replacement). Finally dolomite grains are partially dissolved resulting in the creation of microporosity (Stage 3: dissolution). The total porosity at the end of stage 1 corresponds to the constant macroporosity assumed for stage 3 . Sample F2-2 is the lowest porosity sample and its porosity level is close to the mean macroporosity of the whole sample set which has been used to define the constant macroporosity level of $7 \%$ for stage 3 . This sample has then been considered as representative of the beginning of stage 3. The five other samples have then been reported on the porosity evolution curves according to their total porosity.

The blue curves in Figure 9B summarizes the evolution of the total porosity, the microporosity and the macroporosity for F2 model. Once again we observe a good agreement when we compare the elastic waves velocities computed through direct effective medium 
modieling to the experimental data (blue data in Figure 10A). Finally, Figure 10C presents the evolution of the elastic velocities during diagenesis together with the measured velocities reported according to the above-described time calibration. Due to the different initial states considered for the diagenesis modeling, the modeled range of velocity evolution is smaller for Family 2 than for Family 1 . indeed, the initial state considered for Family 1 corresponds to the initial carbonate mud with a high porosity level whereas the initial state considered for Family 2 corresponds to a more advanced state in the sediment history associated to a low-porosity rock. The creation of macroporosity during stage 1 is naturally associated with a velocity decrease. The replacement of calcite by dolomite during stage 2 leads to an increase in P- and S-wave velocities, as previously intuited from the comparison of the experimental ultrasonic data obtained on F1 and F2 samples. Finally the transformation of the dolomite phase into microporous grains during stage 3 leads to a relatively sharp velocity decrease. As expected from their different porosity levels, sample F2-4 appears to be representative of an intermediate diagenetic state between sample F2-2 (beginning of stage 3) and samples F2-3, F2-5, F2-6 and F2-7 (end of Stage 3).

\section{DISCUSSION}

The temporal calibration phase of the effective medium model is the most difficult to achieve due to the different diagenesis phases recorded on a same thin section for which only relative timings are available. Due to the lack of data on the absolute date of each diagenetic event, the time evolution is obviously arbitrary at the moment. To tackle this issue advanced petrographic analysis could be added to the experimental characterization workflow, such as the 
characterization of carbonate $\mathrm{U}-\mathrm{Pb}$ isotopes via laser ablation, to obtain absolute timing for each diagenesis phase (Vahrenkamp et al., 2014; Mangenot et al., 2018). As this is not the primary objective of this paper, we choose to display the modeling results in a rock physics template that does not involve time. Figure 11 plots the evolution of the elastic properties together with the experimental results in the standard $V_{P} / V_{S}$ ratio versus P-wave impedance template.

The modeling results provided for F1 carbonate formation do not show distinct area for each diagenetic stage. The end of stage 1 and stages 2 and 3 are associated to $V_{P} / V_{S}$ ratios within the measurement error. Moreover, in this representation, the experimental data somewhat deviate from the modeling data. On the contrary, the different stages characterizing the diagenesis of F2 carbonate formation clearly follow a specific path within the $I_{P}-V_{P} / V_{S}$ space. The six F2 samples are located at the end of the diagenetic path, according to the time calibration based on porosity and velocity data. Samples F2-2 and F2-4 appear to be representative of an earlier stage of diagenesis, such as previously described. Note that sample F2-2 is the most cemented sample which could explain the higher observed discrepancy.

One key question remains open: can the experimental velocities measured on the studied samples be considered as having been only differently affected during the last diagenetic stage or are they the integration of all the successive diagenetic processes experienced more or less intensely by the samples? The second option is naturally more likely and could explain some differences observed for F1 samples. To implement the proposed approach in a more consistent way, we will have to consider additional information from basin modeling to assess the residence time of each sample within the different diagenetic stages. 
Finaliy, to explore further avenues, we test the possibility of predicting the evolution of permeability curing diagenesis based on our effective medium modeling approach. Numerous much more adapted approaches exist in the literature to model permeability in rocks (e.g. Dou et a!., 2011; Ba et al., 2013). But our objective is to predict permeability using microstructural models weli constrained by geological and mechanical data. The idea is only to replace pure phase mechanical parameters by flow parameters (permeability) (Table 5). Effective medium modeling is then applied to calculate a homogenized permeability tensor at the macroscale (Barthélémy, 2009). Figure 12 presents the results of this extrapolation to permeability prediction. No calibration with experimental data has been performed here. The only objective is to illustrate the impact of the different diagenetic stages on the permeability response.

\section{CONCLUSION}

It is generally difficult to properly modei acoustic properties of carbonate rocks due to the numerous control factors. We base our modeling approach on an extensive experimental dataset that we use to constrain the conceptual effective medium model and assess the microscopic properties. Contrary to standard approach, we do not introduce compliant pores in our model to reproduce the measured velocity, which is consistent with the observations on thin sections. We reproduce the grain contact behavior by adding a compliant interface to carbonate grains. The normal and tangential stiffness of this interface are determined through inverse analysis of the measured elastic velocity. We then perform direct calculations to define velocity - porosity trends during diagenesis.

Our approach has to be improved by adding other experimental constraints, such as real timing of diagenetic stages. However, it appears as a simple but realistic approach to fill the gap 
between the petrophysical evolution of carbonates during diagenesis and their elastic properties.

All parts of a carbonate formation have not been affected by the same diagenetic events. This approach could then be used to test the impact of different diagenesis scenarios on the elastic response of carbonate rocks. Results of such modeling could provide improved input data to perform synthetic seismic from stratigraphic models populated with velocity data. 
Geophysics

\section{BIBLIOGRAPHY}

Adam, L., Batzle, M., Brevik, I., 2006, Gassmann's fluid substitution and shear modulus variability in carbonates at laboratory seismic and ultrasonic frequencies: Geophysics, 71(6), $173-183$.

Adelinet, M., Fortin, J., Guéguen, Y., Schubnel, A. and Geoffroy, L., 2010, Frequency and fluid effects on elastic properties of basalt: Experimental investigations: Geophysical Research Letters, 37(2).

Adelinet, M., Fortin, J., Schubnel, A. and Guéguen, Y., 2013, Deformation modes in an Icelandic basalt: From brittle failure to localized deformation bands: Journal of Volcanology and Geothermal Research, 255, 15-25.

Alvarez J. P. G., 2007, Effect of microstructure and pore fluid on the elastic properties of carbonate rocks: PhD Thesis, University of Oklahoma.

Ba, J., Cao, H., Carcione, J. M., Tang, G., Yan, X. F., Sun, W. T. and Nie, J. X., 2013, Multiscale rock-physics templates for gas detection in carbonate reservoirs: Journal of Applied Geophysics, 93, 77-82.

Baechle, G. T., Colpaert, A., Eberli, G. P. and Weger, R. J., 2008, Effects of microporosity on sonic velocity in carbonate rocks: The Leading Edge, 27(8), 1012-1018.

Barthélémy, J. F., 2005, Approche micromécanique de la rupture et de la fissuration dans les géomatériaux: PhD Thesis (in French), Ecole Nationale des Ponts et Chaussées. 
Geophysics

Barthélémy, J. F., 2009, Effective permeability of media with a dense network of long and micro fractures: Transport in porous media, 76(1), 153-178.

Baud, P., Vinciguerra, S., David, C., Cavallo, A., Walker, E. and Reuschlé, T., 2009, Compaction and failure in high porosity carbonates: Mechanical data and microstructura! observations: Pure appl. geophys., 166, 869-898.

Bemer, E., Hamon, Y. and Adelinet, M., 2017, Integrated Characterization Workflow to Assess Diagenesis Impact on the Petrophysical and Petroacoustic Properties of Carbonate Reservoirs, in M. Vandamme, J.-M. Pereira, P. Dangla and S. Ghabezlo eds., Poromechanics VI: Proceedings of the Sixth Biot Conference on Poromechanics, 1884-1891.

Bemer, E., Adelinet, M. and Hamon, Y., 2018, Consistent experimental investigation of the applicability of Biot-Gassmann's equation in carbonates, Geophysics, this issue.

Brigaud, B., Vincent, B., Durlet, C., Deconinck, J.-F., Blanc, P. and Trouiller, A., 2010, Acoustic Properties of Ancient Shallow-Marine Carbonates: Effects of Depositional Environments and Diagenetic Processes (Middle Jurassic, Paris Basin, France): Journal of Sedimentary Research 80, 791-807.

Cadoret, T., Marion, D. and Zinszner, B., 1995, Influence of frequency and fluid distribution on elastic wave velocities in partially saturated limestones: J. Geophys. Res., 100(B6), 9789-9803. 
Geophysics

Carpentier, C., Ferry, S., Lécuyer, C., Strasser, A., Géraud, Y. and Trouiller, A., 2015, Origin of micropores in late Jurassic (Oxfordian) micrites of the Eastern Paris Basin, France: Journal of Sedimentary Research, 85(6), 660-682.

Casteleyn, L., Robion, P., Collin, P.-Y., Menéndez, B., David, C., Desaubliaux, G., Fernandes, N., Dre:tx, R., Badiner, G. and Brosse, E., 2010, Interreiations of the petrophysical, sedimentological and microstructural properties of the Oolithe Blanche Formation (Bathonian, saline aquifer of the Paris Basin): Sedimentary Geology, 230, 123-138.

Casteleyn, L., Robion, P., David, C., Collin, P.-Y., Menéndez, B., Fernandes, N., Desaubliaux, G. and Rigollet, C., 2011, An integrated study of the petrophysical properties of

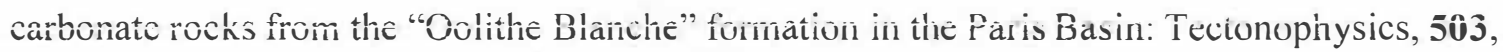
18-33.

Choquette P.W. and Pray L.C., 1970, Geologic nomenclature and classification of porosity in sedimentary carbonates: AAPG Bulletin, 54, 207-244.

Clark, A. C. and Vanorio, T. (2016). The rock physics and geochemistry of carbonates exposed to reactive brines: Journal of Geophysical Research: Solid Earth, 121(3), 1497-1513.

Dickson J.A.D., 1966, Carbonate identification and genesis as revealed by staining: Journal of Sedimentary Petrology, 36(2), 491-505.

Dou, Q., Sun, Y. and Sullivan, C., 2011, Rock-physics-based carbonate pore type characterization and reservoir permeability heterogeneity evaluation, Upper San Andres reservoir, Permian Basin, west Texas: Journal of Applied Geophysics, 74(1), 8-18. 
Geophysics

Dunham R.J., 1962, Classification of Carbonate Rocks according to depositional texture, in W.E. Ham, eds., Classification of Carbonate Rocks: AAPG Memoir, 1, 108-121.

Dvorkin, J., Mavko, G. and Nur A., 1995, Squirt flow in fully saturated rocks: Geophysics, 60(1), 97-107.

Eberli, G. P., Baechle, G. T., Anselmetti, F. S. and Incze, M. L., 2003, Factors controlling elastic properties in carbonate sediments and rocks: The Leading Edge, 22(7), 654-660.

Eiler, J. M., 2011, Paleoclimate reconstruction using carbonate clumped isotope thermometry: Quaternary Science Reviews, 30(25-26), 3575-3588.

Esheiby, J.D., i957, The determination of the eiastic fieid of an eiiipsoidai inciusion, and related problems: Proc. Roy. Soc. London, 376-396.

Fleury M .and Soualem J., 2009, Quantitative analysis of diffusional pore coupling from $\mathrm{T}_{2}$-store- $\mathrm{T}_{2}$ NMR experiments: J. Coll. Inter. Sciences, 336.

Fournier, F., Pellerin, M., Villeneuve, Q., Teillet, T., Hong, F., Poli, E., Borgomano, J., Léonide P. and Hairabian, A., 2018, The equivalent pore aspect ratio as a tool for pore type prediction in carbonate reservoirs: AAPG Bulletin,102(7), 1343-1377.

Heydari, E., 2003, Meteoric versus burial control on porosity evolution of the Smackover Formation. AAPG Bulletin, 87(11), 1779-1797. 
Geophysics

Kelts, K. and Talbot, M., 1990, Lacustrine carbonates as geochemical archives of environmental change and biotic/abiotic interactions, in M.M. Tiizer and C. Serruya, eds., Large Lakes: Brokc/Springer Series in Contemporary Bioscience, 288-315.

Lambert, L., Durlet, C., Loreau, J.-P. and Marnier, G., 2006, Burial dissolution of micrite in Middle East carbonate reservoirs (Jurassic-Cretaceous): keys for recognition and timing: Marine and Petroleum Geology 23, 79-92.

Lønøy, A., 2006, Making sense of carbonate pore system: AAPG Bulletin, 90(9), 13811405.

Makhloufi, Y., Collin, P.-Y., Bergerat, F., Casteleyn, L., Claes, S., David, C., Menéndez, B., Monna, F., Robion, P. and Sizun, J.-P., 2013, Impact of sedimentology and diagenesis on the petrophysical properties of a tight oolitic carbonate reservoir. The case of the Oolithe Blanche Formation (Bathonian, Paris Basin, France): Mar. Pet. Geol., 48, 323-340.

Mangenot, X., Gasparrini, M., Rouchon, V. and Bonifacie, M., 2018, Basin-scale thermal and fluid flow histories revealed by carbonate clumped isotopes ( $\Delta 47)$-Middle Jurassic carbonates of the Paris Basin depocentre: Sedimentology, 65(1), 123-150.

Matonti, C., Guglielmi, Y., Viseur, S., Bruna, P. O., Borgomano, J., Dahl, C. and Marié, L., 2015, Heterogeneities and diagenetic control on the spatial distribution of carbonate rocks acoustic properties at the outcrop scale: Tectonophysics, 638, 94-111.

Matonti, C., Bourget, J., Fournier, F., Riera, R., Haig, D., Håkansson, E., Pellerin, M., Hong, F. and Reijmer, J., 2016, Impact of Contrasted Diagenetic History on the Pore Type and 
Geophysics

Acoustic Properties Acquisition of Non-Tropical Carbonates (Cape Range, Western Australia): AGU Fall Meeting Abstracts.

Mavko, G., Mukerji, T. and Dvorkin, J., 1998, The Rock Physics handbook: Toois for seismic analysis in porous media: Cambridge University Press.

Nader, F., Champenois, F., Barbier, M., Adelinet, M., Rosenberg, E., Houel, P., Delmas, J. and Swennen, R., 2016, Diagenetic effects of compaction on reservoir properties: The case of Lower Callovian "Dalle Nacrée" Formation (Paris Basin, France): Journal of Geodynamics, 101, $5-29$.

Neveux, L., Grgic, D., Carpentier, C., Pironon, J., Truche, L. and Girard, J. P., 2014, Experimental simulation of chemomechanical processes during deep burial diagenesis of carbonate rocks: Journal of Geophysical Research: Solid Earth, 119(2), 984-1007.

Nicolas, A., Fortin, J., Regnet, J. B., Dimanov, A. and Guéguen, Y., 2016, Brittle and semi-brittle behaviours of a carbonate rock: influence of water and temperature: Geophysical Journal International, 206(1), 438-456.

Rasolofosaon, P. and Zinszner, B., 2003, Petroacoustic Characterization of Reservoir Rocks For Seismic Monitoring Studies Laboratory Measurement of Hertz and Gassmann Parameters: Oil Gas Sci. Technol. - Rev. IFP, 58(6), 615-635.

Rasolofosaon, P., Lucet, N. and Zinszner, B., 2008, Petroacoustics of carbonate reservoir rocks: The Leading Edge, 27(8), 1034-1039. 
Geophysics

Regnet, J. B., Robion, P., David, C., Fortin, J., Brigaud, B. and Yven, B., 2015a, Acoustic and ieservoir properties of inicroporous carbonate rocks: Implication of micrite particle size and morphology: Journal of Geophysical Research: Solid Earth, 120(2), 790-811.

Regnet, J. B., David, C., Fortin, J., Robion, P., Makhloufi, Y. and Collin, P. Y., 2015b, Influence of microporosity distribution on the mechanical behavior of oolithic carbonate rocks: Geomechanics for Energy and the Environment, 3, 11-23.

Regnet, J.B., Fortin, J., Nicolas, A., Pellerin, M. and Guéguen, Y., 2018, Elastic properties of continental carbonate analogs: from controlling factors to an applicable model for acoustic velocity predictions. Geophysics, accepted.

Riding, R., 1991, Classification of microbial carbonates, in R. Riding, ed., Calcareous algae and stromatolites, Springer, 21-51.

Sibley, D. F. and Gregg, J., 1987, Classification of Dolomite Rock Texture: Journal of sedimentary petrology, 57, 967-975.

Vahrenkamp, V., Barata, J., Van Laer, P. J., Swart, P. and Murray, S., 2014, Micro Rhombic Calcite of a Giant Barremian (Thamama B) Reservoir Onshore Abu Dhabi-Clumped Isotope Analyses fix Temperature, Water Composition and Timing of Burial Diagenesis: SPE172033-MS.

Vajdova, V., Baud, P. and Wong, T. F., 2004, Compaction, dilatancy, and failure in porous carbonate rocks: Journal of Geophysical Research: Solid Earth, 109(B5). 
Verwer, K., Braaksma, H. and Kenter, J. A., 2008, Acoustic properties of carbonates:

Effects of rock texture and implications for fluid substitution: Geophysics, 73(2), B51-B65.

Vincent B., Fleury M., Santerre Y. and Brigaud B., 2011, NMR relaxation of neritic carbonates: an integrated petrophysical and petrographical approach. Journal of Applied Geophysics, 74, 38-58.

Xu, S. and Payne, M. A., 2009, Modeling elastic properties in carbonate rocks: The Leading Edge, 28(1), 66-74.

Xu, S.Y. and White, R.E., 1996, A physical model for shear-wave velocity prediction: Geophysical Prospecting, 44, 687-717.

Zhao, L., Nasser, M. and Han, D., 2013, Quantitative geophysical pore-type characterization and its geological implication in carbonate reservoirs: Geophysical Prospecting, 61, 827-841.

\section{LIST OF TABLES}

Table 1. Quantitative estimation of the different components observed in the scanned thin sections. Proportions within bracket are normalized with respect to the solid content (i.e. by removing the porosity from the calculations) ............................................................................. 36 Table 2. Sample mineral contents deduced from XRD analysis (expressed in volume

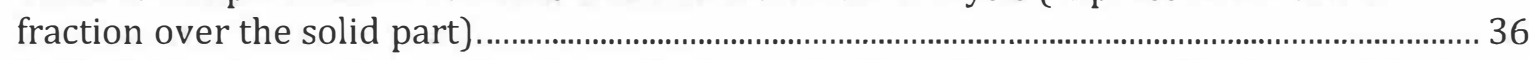
Table 3. Total porosity and fractions of microporosity and macroporosity deduced from NMR measurements. Values in bracket provided for sample F1-13 correspond to the microporosity and macroporosity fractions derived from microscanner imaging. ................. 37 Table 4. Ultrasonic velocities measured on brine-saturated samples. ..........................................37 Table 5. Pure phase moduli used in the effective medium approach (Mavko et al., 1998) and arbitrary permeability attributed to these phases.

\section{Tables}


Table 1. Quantitative estimation of the different components observed in the scanned thin sections. Proportions within bracket are normalize with respect to the solid content (i.e. by removing the porosity from the calculations).

\begin{tabular}{ccccc} 
Sample & Calcite & Dolomite & Quartz & $\begin{array}{c}\text { Resolved } \\
\text { porosity }\end{array}$ \\
\hline F1-12 & $64 \%(75 \%$ norm. $)$ & $21 \%(24 \%$ norm. $)$ & $<1 \%(1 \%$ norm. $)$ & $14 \%$ \\
\hline F1-13 & $81 \%(94 \%$ norm. $)$ & $4 \%(5 \%$ norm. $)$ & $<1 \%(1 \%$ norm. $)$ & $14 \%$ \\
\hline F1-15 & $80 \%(87 \%$ norm. $)$ & $11 \%(12 \%$ norm. $)$ & $<1 \%(1 \%$ norm. $)$ & $8 \%$ \\
\hline F1-17 & $67 \%(82 \%$ norm. $)$ & $13 \%(16 \%$ norm. $)$ & $<1 \%(1 \%$ norm. $)$ & $18 \%$ \\
\hline F1-21 & $76 \%(84 \%$ norm. $)$ & $14 \%(15 \%$ norm. $)$ & $<1 \%(1 \%$ norm. $)$ & $9 \%$ \\
\hline F2-2 & $27 \%(27 \%$ norm. $)$ & $73 \%(73 \%$ norm. $)$ & $0 \%(0 \%$ norm. $)$ & $0.4 \%$ \\
\hline F2-3 & $3 \%(3 \%$ norm. $)$ & $94 \%(97 \%$ norm. $)$ & $0 \%(0 \%$ norm. $)$ & $3 \%$ \\
\hline F2-4 & $1 \%(1 \%$ norm. $)$ & $95 \%(99 \%$ norm. $)$ & $0 \%(0 \%$ norm. $)$ & $4 \%$ \\
\hline F2-5 & $1 \%(1 \%$ norm. $)$ & $97 \%(99 \%$ norm. $)$ & $0 \%(0 \%$ norm. $)$ & $2 \%$ \\
\hline F2-6 & $0 \%(0 \%$ norm. $)$ & $95 \%(100 \%$ norm. $)$ & $0 \%(0 \%$ norm. $)$ & $5 \%$ \\
\hline F2-7 & $0 \%(0 \%$ norm. $)$ & $95 \%(100 \%$ norm. $)$ & $0 \%(0 \%$ norm. $)$ & $5 \%$ \\
\hline
\end{tabular}

Table 2. Sample mineral contents deduced from XRD analysis (expressed in volume fraction over the solid part).

\begin{tabular}{ccccc} 
Sample & Calcite & Dolomite & Silicate \\
\hline $\mathbf{1 2}$ & $52.1 \%$ & $36.1 \%$ & $11.8 \%$ \\
\hline $\mathbf{1 3}$ & $78.3 \%$ & $19.3 \%$ & $2.4 \%$ \\
\hline $\mathbf{1 5}$ & $67.6 \%$ & $25.0 \%$ & $7.4 \%$ \\
\hline $\mathbf{1 7}$ & $81.0 \%$ & $12.7 \%$ & $6.3 \%$ \\
\hline $\mathbf{2 1}$ & $82.4 \%$ & $13.5 \%$ & $4.1 \%$ \\
\hline $\mathbf{2}$ & $41.5 \%$ & $56.2 \%$ & $2.3 \%$ \\
\hline $\mathbf{3}$ & $8.4 \%$ & $88.3 \%$ & $3.4 \%$ \\
\hline $\mathbf{4}$ & $0.1 \%$ & $96.5 \%$ & $3.4 \%$ \\
\hline $\mathbf{5}$ & $2.5 \%$ & $93.6 \%$ & $3.9 \%$ \\
\hline $\mathbf{6}$ & $0.1 \%$ & $95.6 \%$ & $4.3 \%$ \\
\hline $\mathbf{7}$ & $0.1 \%$ & $95.9 \%$ & $4.0 \%$ \\
\hline
\end{tabular}


Geophysics

Tabie 3. Total porosity and fractions of microporosity and macroporosity deduced from NMR measurements. Vaiues in bracket provided for sample E1-13 correspond to the microporosity and macroporosity fractions derived from microscanner imaging.

\begin{tabular}{cccc} 
Sample & $\begin{array}{c}\text { NMR } \\
\text { porosity }\end{array}$ & $\begin{array}{c}\text { NMR } \\
\text { microporosity } \\
\text { fraction }\end{array}$ & $\begin{array}{c}\text { NMR } \\
\text { macroporosity } \\
\text { fraction }\end{array}$ \\
\hline $\mathbf{1 2}$ & $14.1 \%$ & $39 \%$ & $61 \%$ \\
\hline $\mathbf{1 3}$ & $15.3 \%$ & $53 \%(27 \% \mu \mathrm{CT})$ & $47 \%(73 \% \mu \mathrm{CT})$ \\
\hline $\mathbf{1 5}$ & $15.1 \%$ & $32 \%$ & $69 \%$ \\
\hline $\mathbf{1 7}$ & $18.9 \%$ & $35 \%$ & $65 \%$ \\
\hline $\mathbf{2 1}$ & $21.7 \%$ & $27 \%$ & $73 \%$ \\
\hline $\mathbf{2}$ & $6.7 \%$ & $77 \%$ & $23 \%$ \\
\hline $\mathbf{3}$ & $20.3 \%$ & $54 \%$ & $47 \%$ \\
\hline $\mathbf{4}$ & $15.3 \%$ & $53 \%$ & $47 \%$ \\
\hline $\mathbf{5}$ & $19.5 \%$ & $78 \%$ & $22 \%$ \\
\hline $\mathbf{6}$ & $22.8 \%$ & $58 \%$ & $42 \%$ \\
\hline $\mathbf{7}$ & $21.4 \%$ & $56 \%$ & $44 \%$ \\
\hline
\end{tabular}

Table 4. Ultrasonic velocities measured on brine-saturated samples.

\begin{tabular}{|c|c|c|c|c|}
\hline \multicolumn{2}{|c|}{ Sample } & $\begin{array}{l}\text { Density } \\
\left(\mathrm{g} / \mathrm{cm}^{3}\right)\end{array}$ & $V_{P}(\mathrm{~km} / \mathrm{s})$ & $V_{S}(\mathrm{~km} / \mathbf{s})$ \\
\hline \multirow{5}{*}{$\bar{I}$} & 12 & 2.428 & 5.024 & 2.656 \\
\hline & 13 & 2.413 & 4.902 & 2.536 \\
\hline & 15 & 2.378 & 4.760 & 2.526 \\
\hline & 17 & 2.363 & 4.622 & 2.580 \\
\hline & 21 & 2.308 & 4.353 & 2.225 \\
\hline \multirow{5}{*}{ I } & 2 & 2.645 & 5.529 & 2.990 \\
\hline & 3 & 2.46 & 4.824 & 2.669 \\
\hline & 4 & 2.556 & 5.284 & 2.925 \\
\hline & 5 & 2.464 & 4.803 & 2.639 \\
\hline & 6 & 2.434 & 4.607 & 2.571 \\
\hline
\end{tabular}


Table 5. Pure phase moduli used in the effective medium approach (Mavko et al., 1998) and arbitrary permeability attributed to these phases.

\begin{tabular}{cccc} 
Mineral phase & $\begin{array}{c}\text { Bulk modulus } \\
(\mathbf{G P a})\end{array}$ & $\begin{array}{c}\text { Shear modulus } \\
(\mathbf{G P a})\end{array}$ & $\begin{array}{c}\text { Permeability } \\
(\mathbf{m D})\end{array}$ \\
\hline Calcite & 77 & 32 & $1.10^{-4}$ \\
\hline Doiomite & 95 & 45 & $1.10^{-2}$ \\
\hline Quartz & 38 & 44 & $1.10^{-4}$ \\
\hline Liquid water & 2.3 & 0 & $\begin{array}{c}1.10^{6} \text { (permeability } \\
\text { of pores) }\end{array}$ \\
\hline Grain interface & Derived from inversion of experimental data & 1 \\
\hline
\end{tabular}




\section{LIST OF FIGURES}

Figure 1. General methodology proposed to model the evolution of carbonate elastic properties during diagenesis.

Figure 2. Petrographic overview of F1 samples (transmitted light plane-polarized

photomicrographs).

Figure 3. Tentative paragenesis for Family 1................................................................................. 41

Figure 4. Petrographic overview of F2 samples (transmitted light plane-polarized photomicrographs).

Figure 5. Tentative paragenesis for Family 2 ……......................................................................... 43

Figure 6. Ultrasonic velocity measurements performed on brine-saturated F1 and F2 samples from family. A: P- and S-wave velocities versus porosity. B: VPVS ratio versus Pwave impedance.....

Figure 7. Conceptual effective medium models evolving with diagenesis. ................................. 44

Figure 8. Petrographic analysis: selected staining thin sections of F1 and F2 samples

illustrating the different key diagenetic events.

Figure 9. Total, macro and microporosity evolution during diagenesis modeling. Data are

displayed in red for F1 carbonates and in blue for F2 carbonates.

Figure 10. Modeling of elastic wave velocities during diagenesis. A: Comparison between model and experimental data in a P-wave velocity versus total porosity diagram. B and C: Evolution of P-wave (bright colors) and S-wave velocities (light colors) during diagenesis. Experimental data are marked as circles for F1 and triangles for F2.

Figure 11. Representation of modeling results in $V P V S$ versus $I_{P}$ rock physics template. The main diagenetic stages are represented with arrows. Experimental data are marked as circles for F1 samples and triangles for F2 samples. Figure 12. Extrapolation to permeability modeling using the same effective medium model evolution.

\section{Figures}

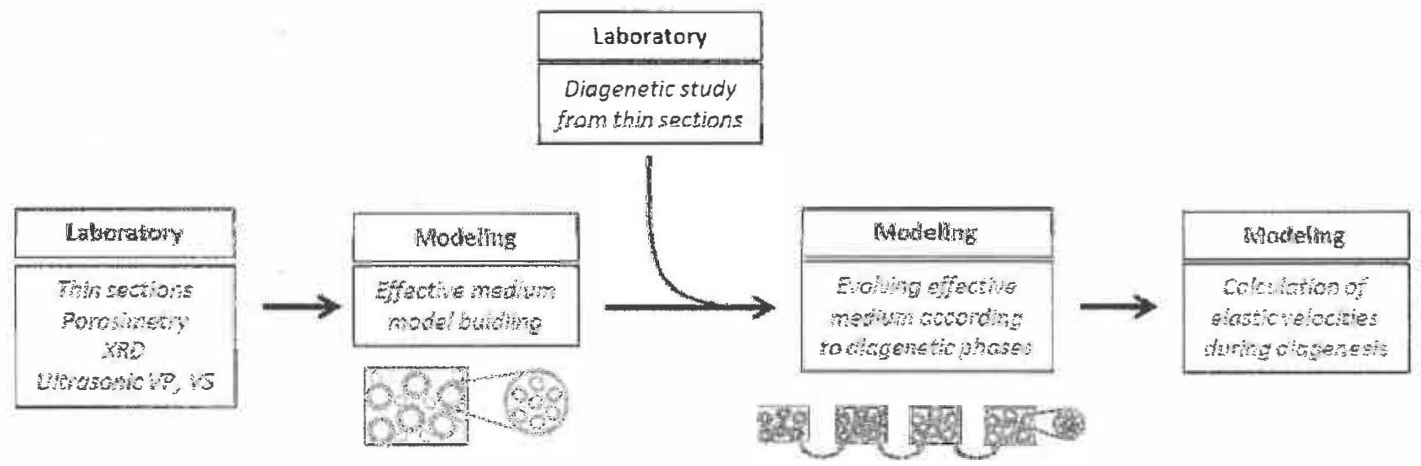

Figure 1. General methodology proposed to model the evolution of carbonate elastic properties during diagenesis. 

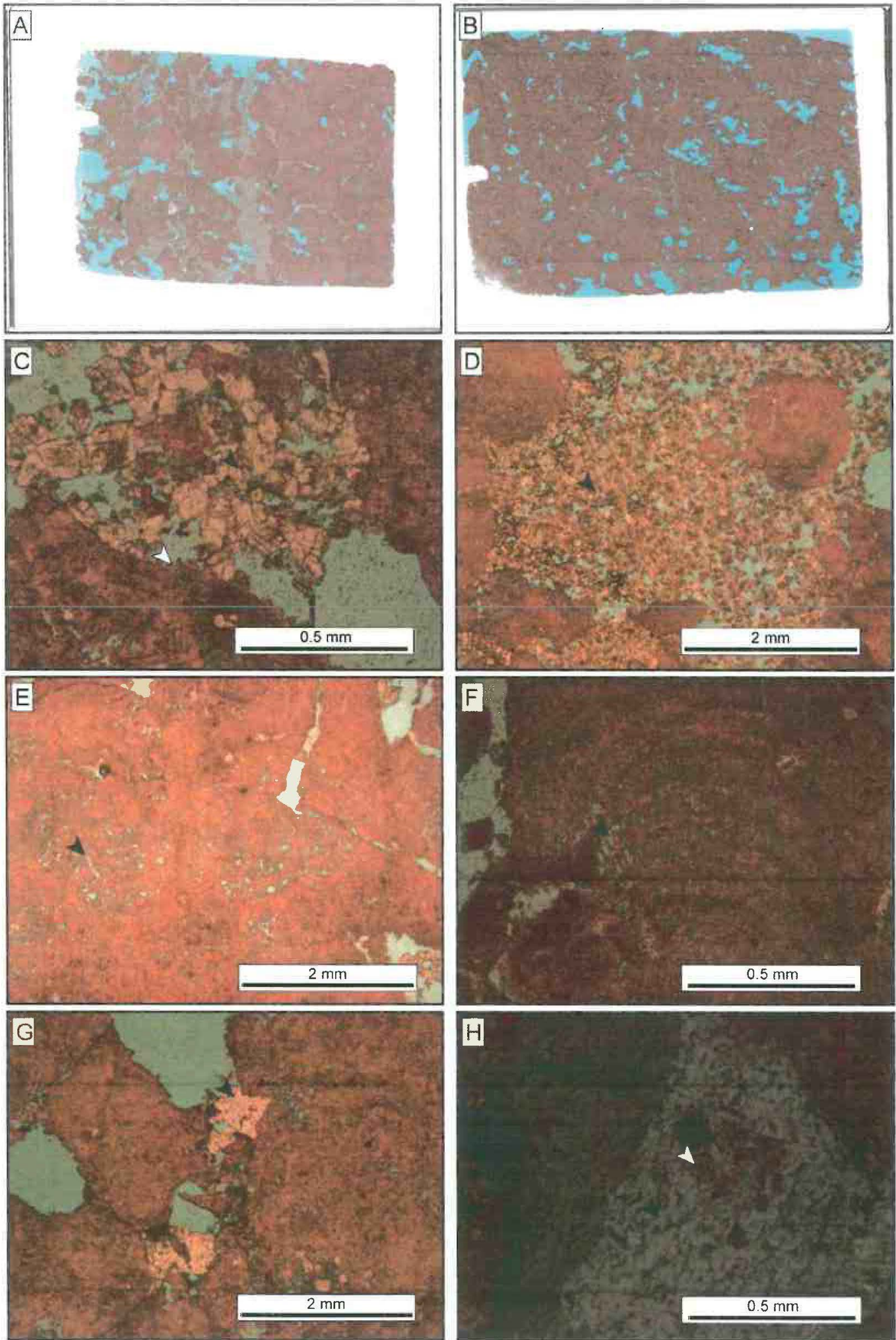
Figure 2. Petrographic overview of F1 samples (transmitted iight plane-polarized photomicrographs).

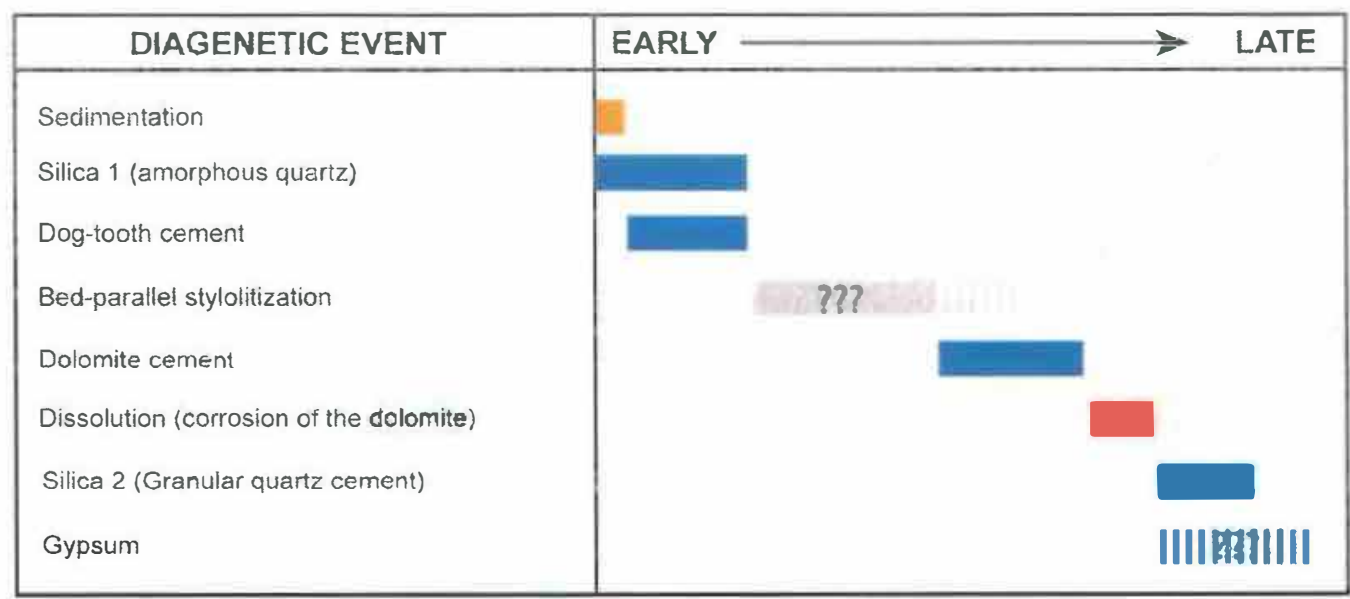

Figure 3. Tentative paragenesis for Family 1. 

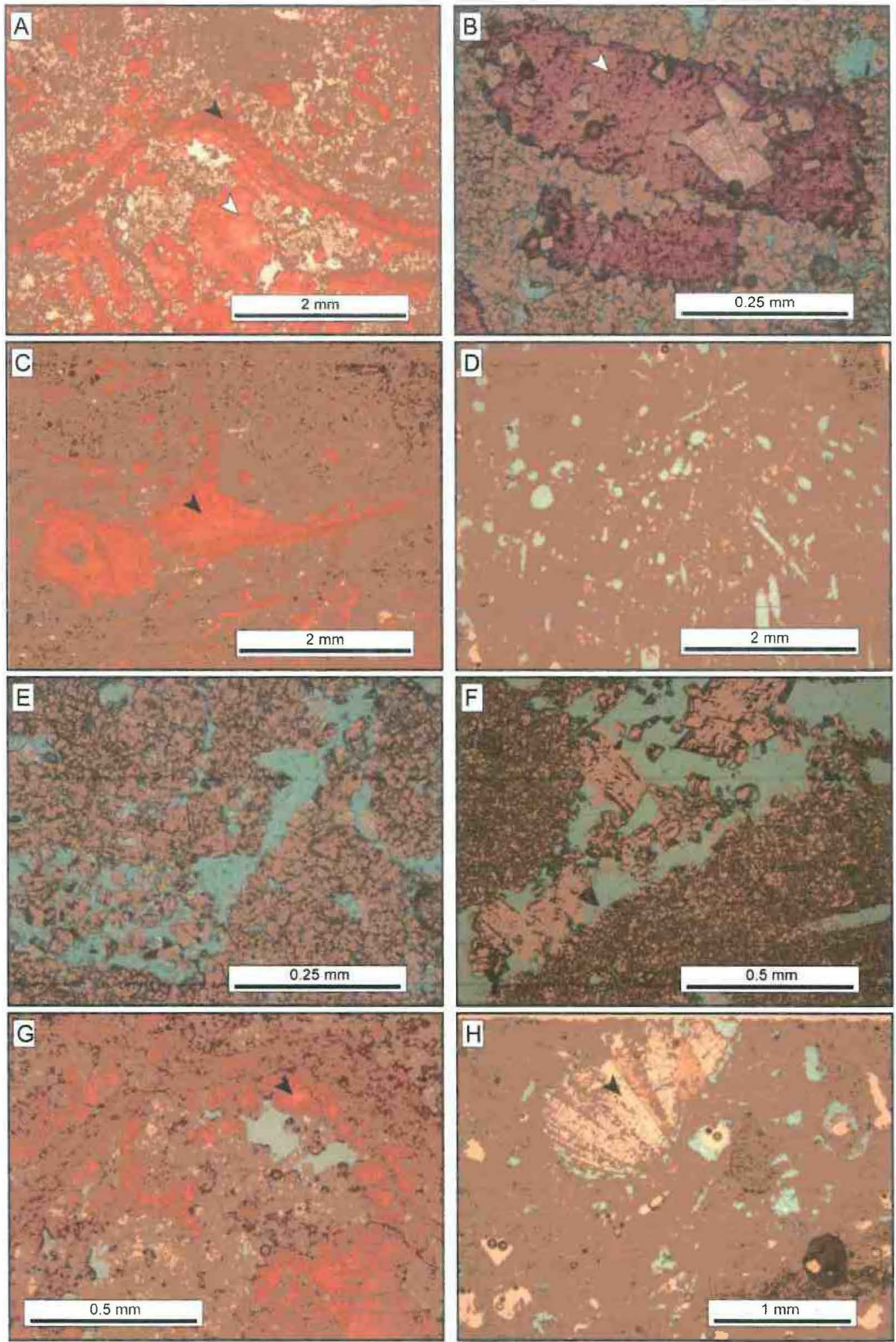
Geophysics

Figure 4. Petrographic overview of F2 samples (transmitted light plane-polarized photomicrographs).

\begin{tabular}{|l|l|}
\hline \multicolumn{1}{|c|}{ DIAGENETIC EVENT } & EARLY $\longrightarrow$ LATE \\
\hline Sedimentation & \\
Syntaxial cement & \\
HMC/aragonite allochems inversion & \\
Dissolution & \\
Dolomite replacement / cement & \\
Equant subhedral, non-ferroan calcite crystals & \\
Gypsum & \\
\hline
\end{tabular}

Figure 5. Tentative paragenesis for Family 2.
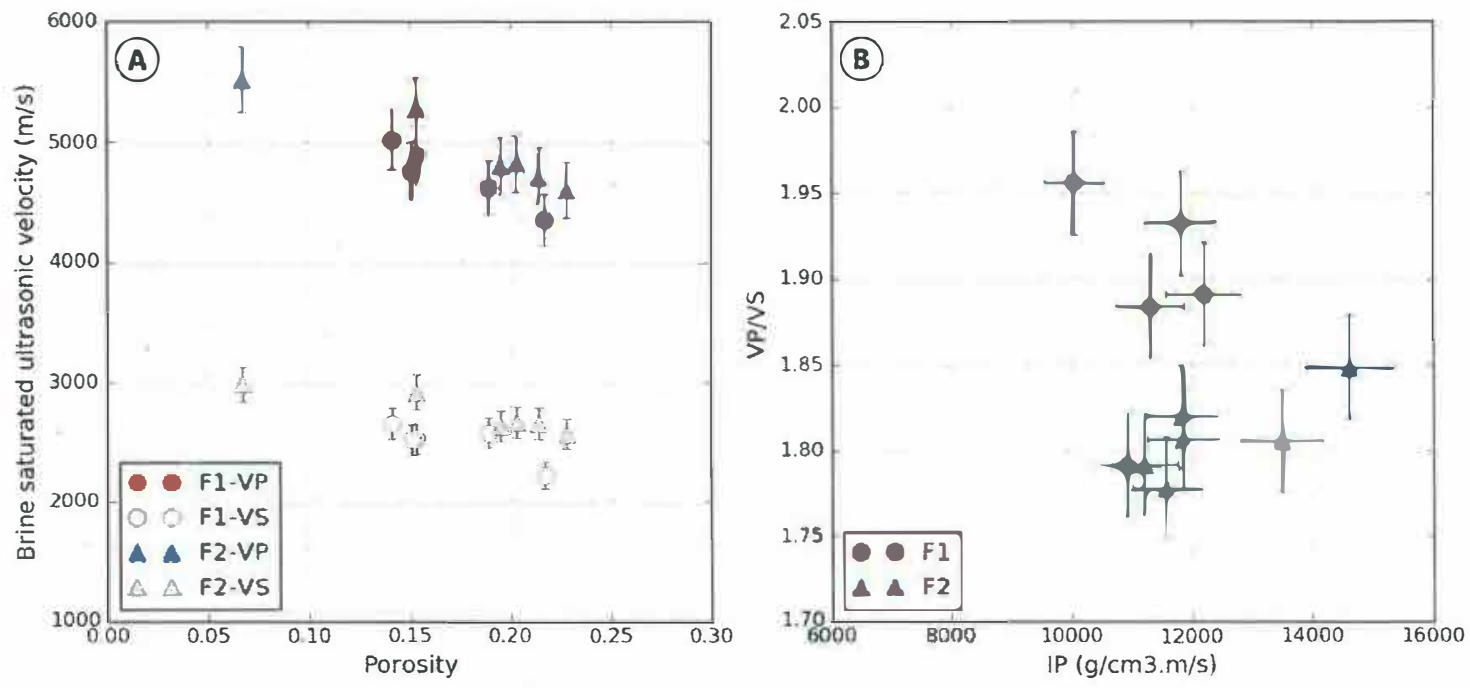

Figure 6. Ultrasonic velocity measurements performed on brine-saturated F1 and F2 samples from family. A: P- and S-wave velocities versus porosity. B: $V_{P} / V_{S}$ ratio versus $\mathrm{P}$-wave impedance. 
Geophysics

A. Family 1
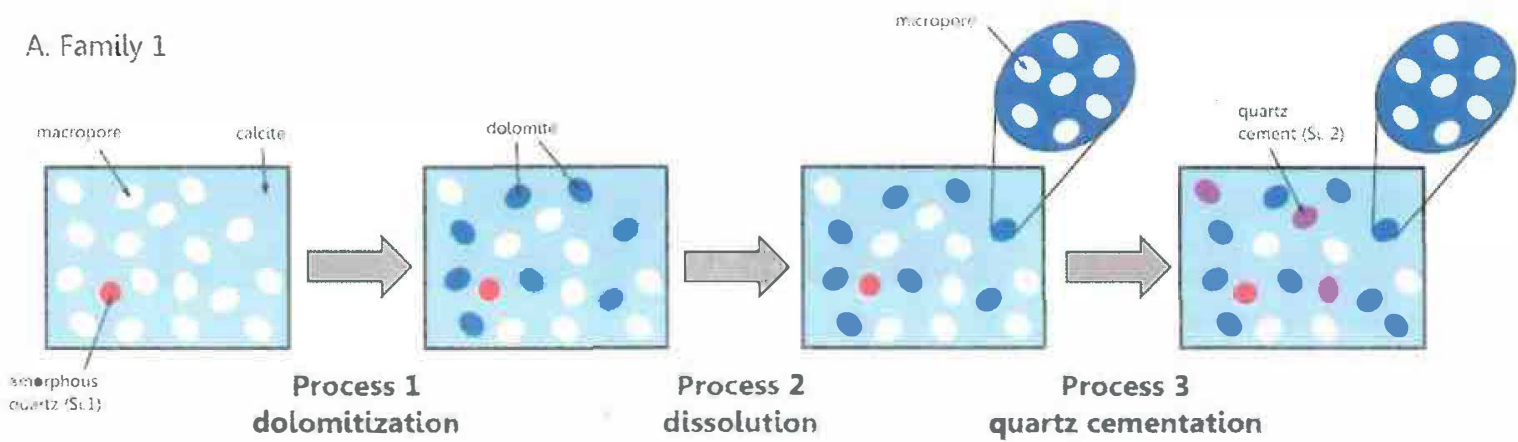

B. Family 2
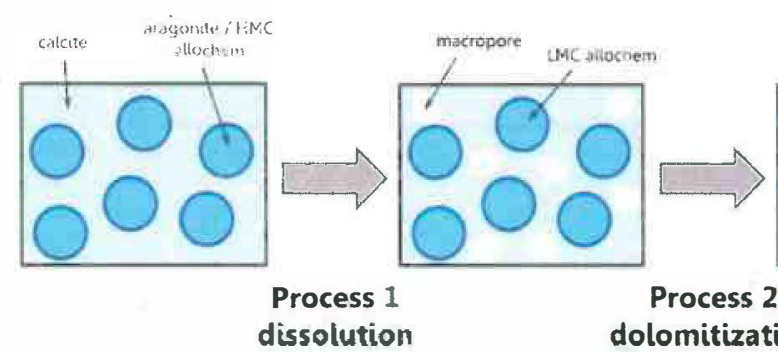

Process 2 dolomitization

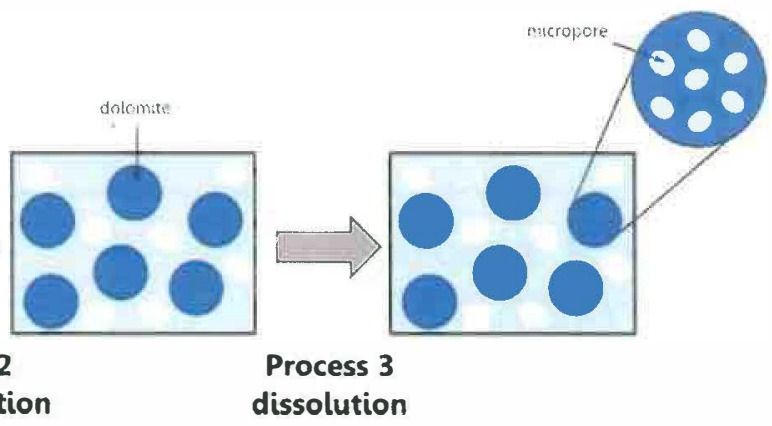

Figure 7. Conceptual effective medium models evolving with diagenesis. 
Geophysics

\section{A. Samples F1}
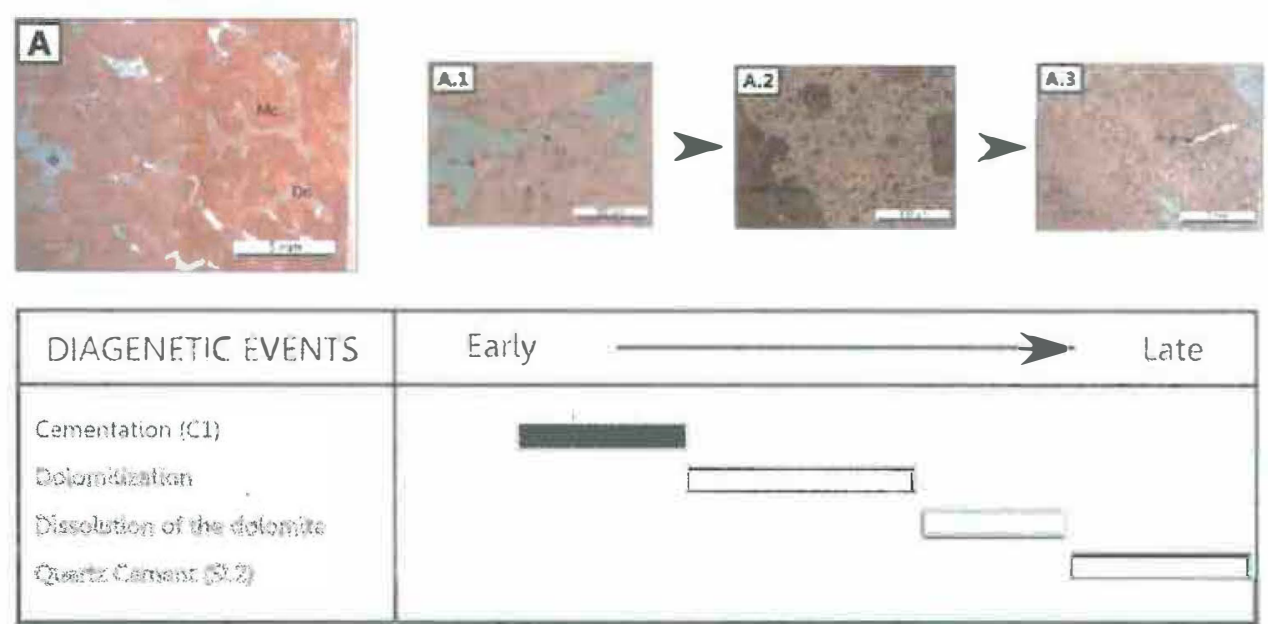

\section{B. Samples F2}
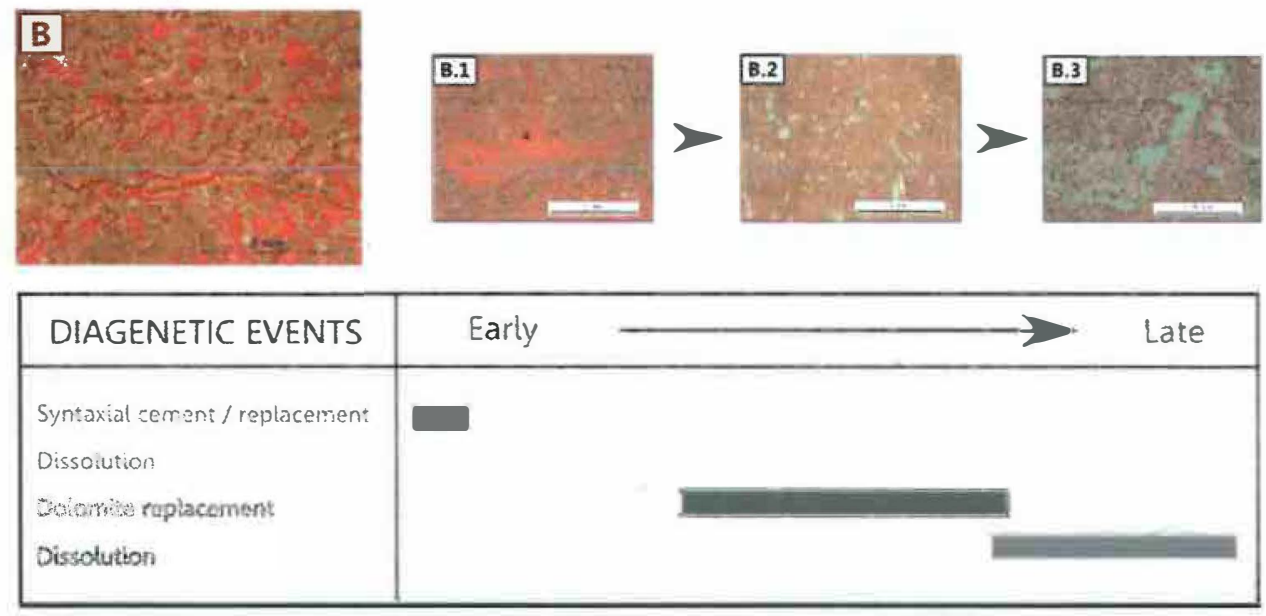

Figure 8. Petrographic analysis: selected staining thin sections of F1 and F2 samples illustrating the different key diagenetic events. 


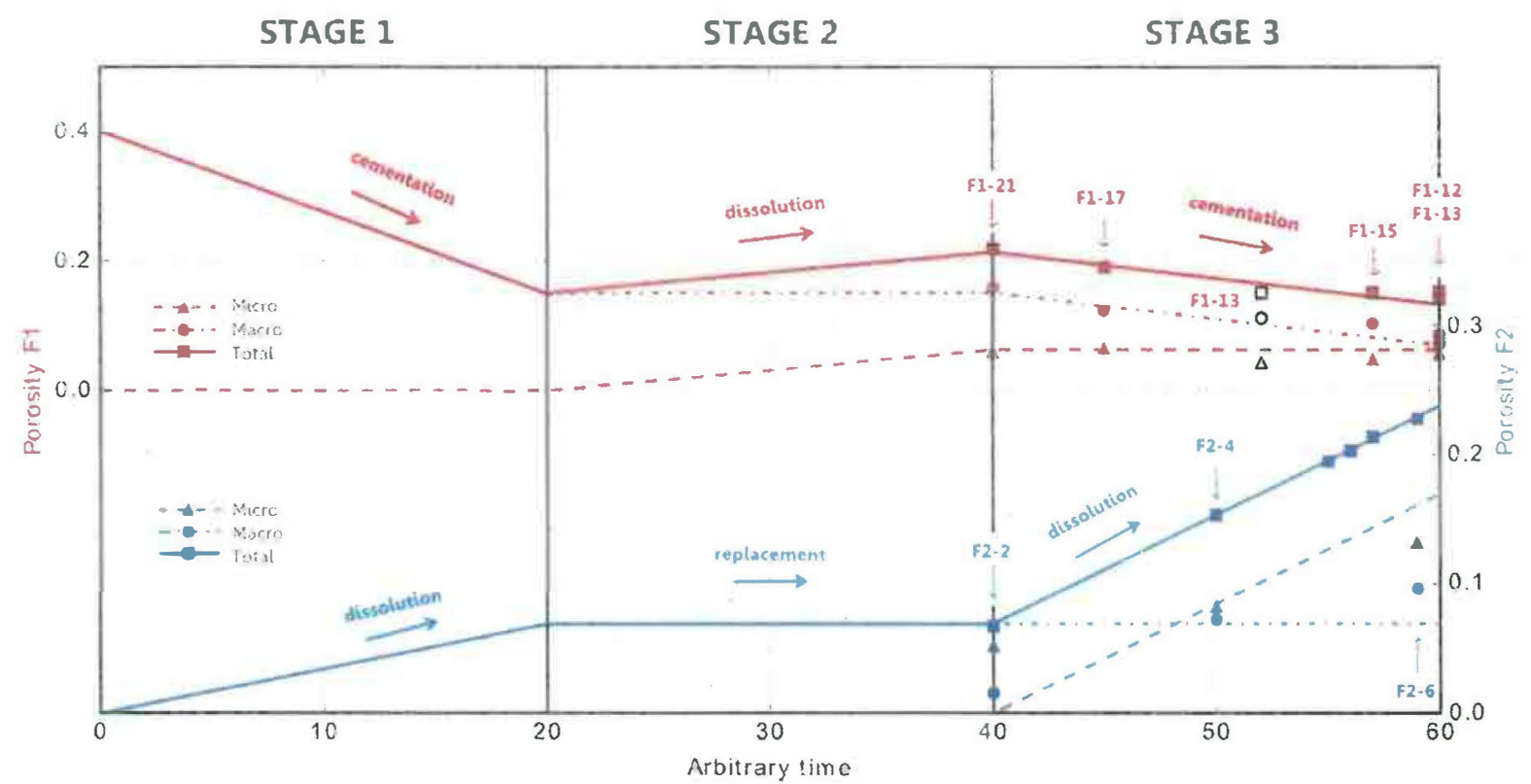

Figure 9. Total, macro and microporosity evolution during diagenesis modeling. Data are displayed in red for F1 carbonates and in blue for F2 carbonates. 

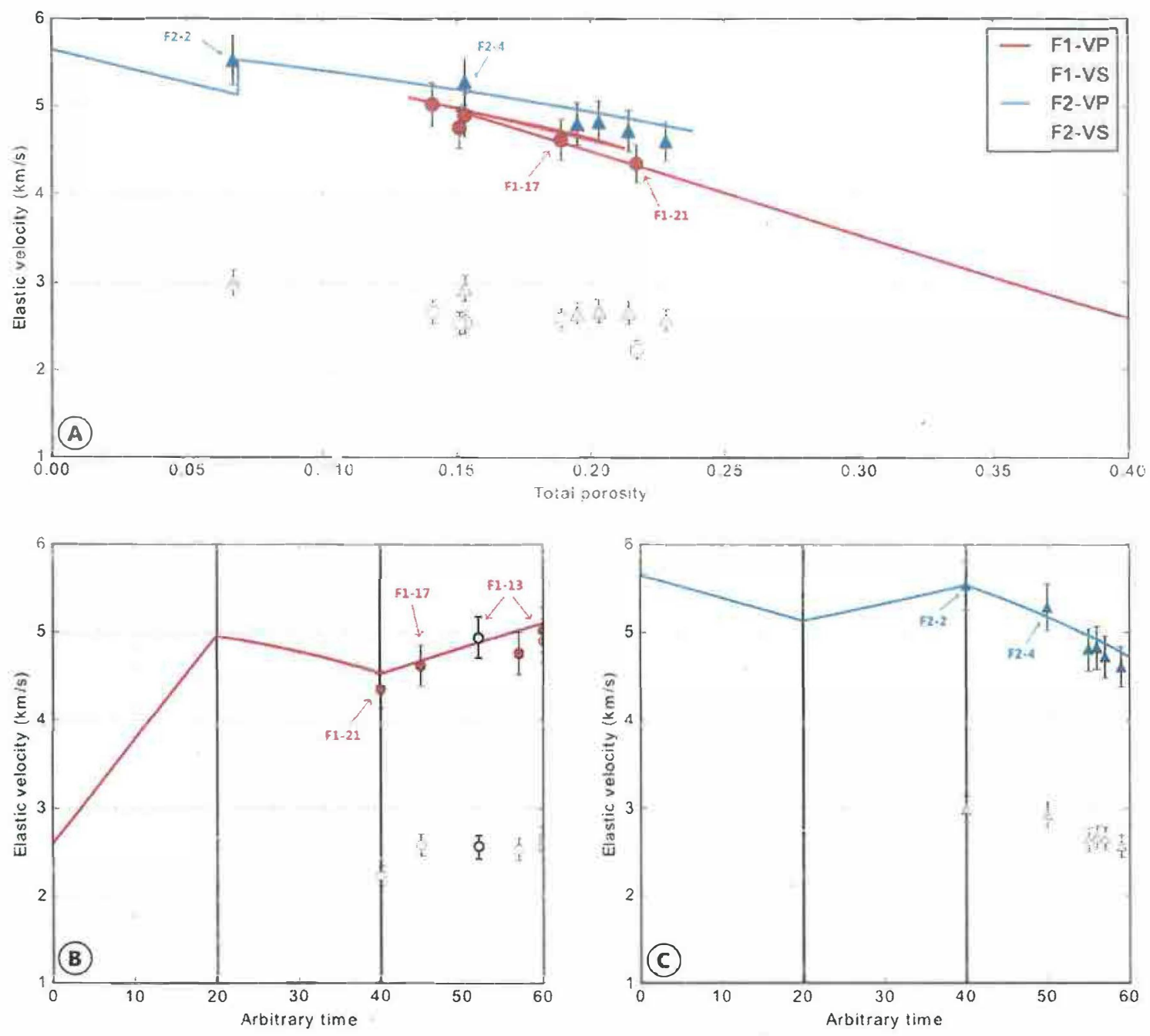

Figure 10. Modeling of elastic wave velocities during diagenesis. A: Comparison between model and experimental data in a P-wave velocity versus total porosity diagram. B and C: Evolution of P-wave (bright colors) and S-wave velocities (light colors) during diagenesis. Experimental data are marked as circles for $\mathrm{F} 1$ and triangles for F2. 


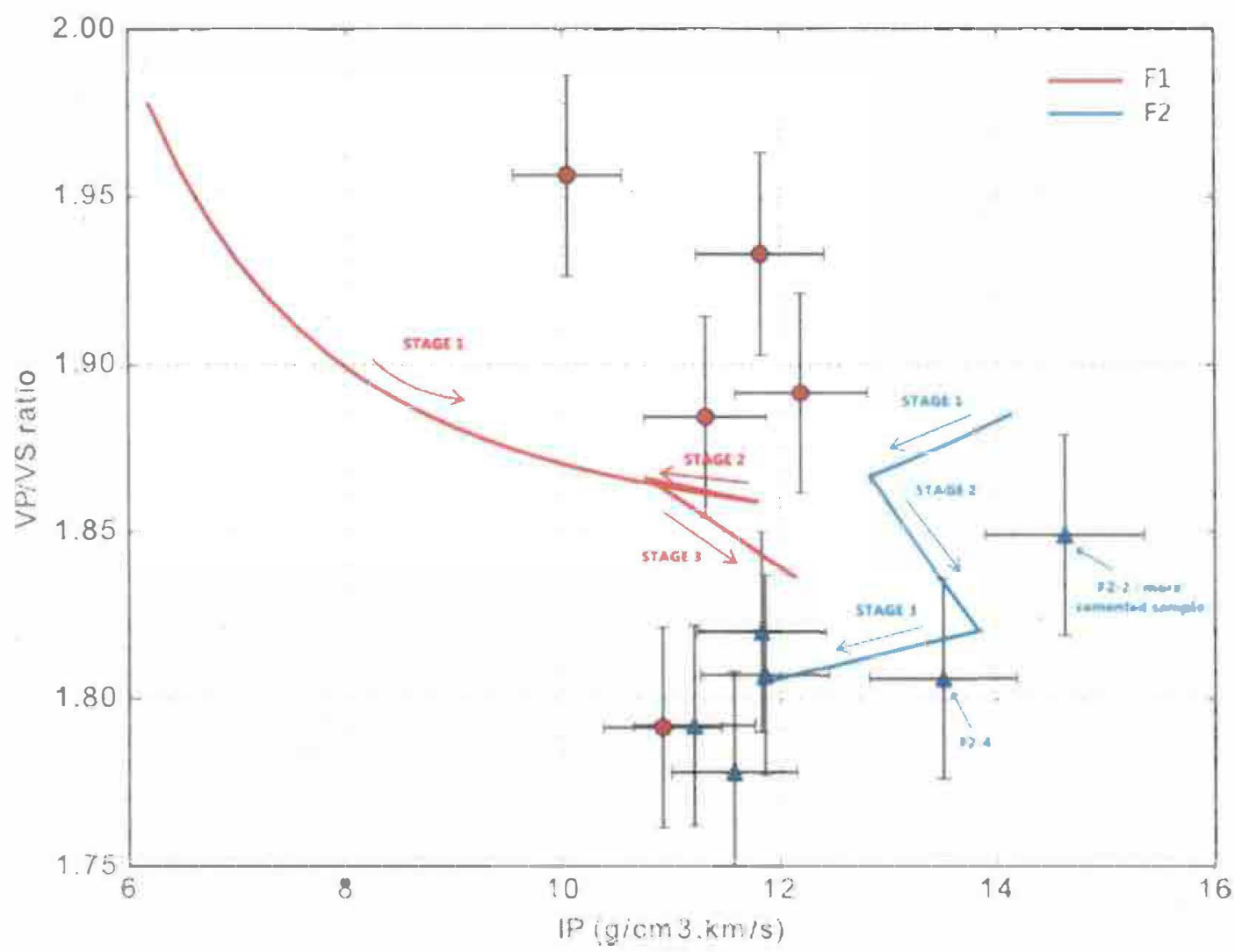

Figure 11. Representation of modeling results in $V_{P} / V_{S}$ versus $I_{P}$ rock physics template. The main diagenetic stages are represented with arrows. Experimental data are marked as circles for F1 samples and triangles for F2 samples. 
1

3

4

5

6

7

8

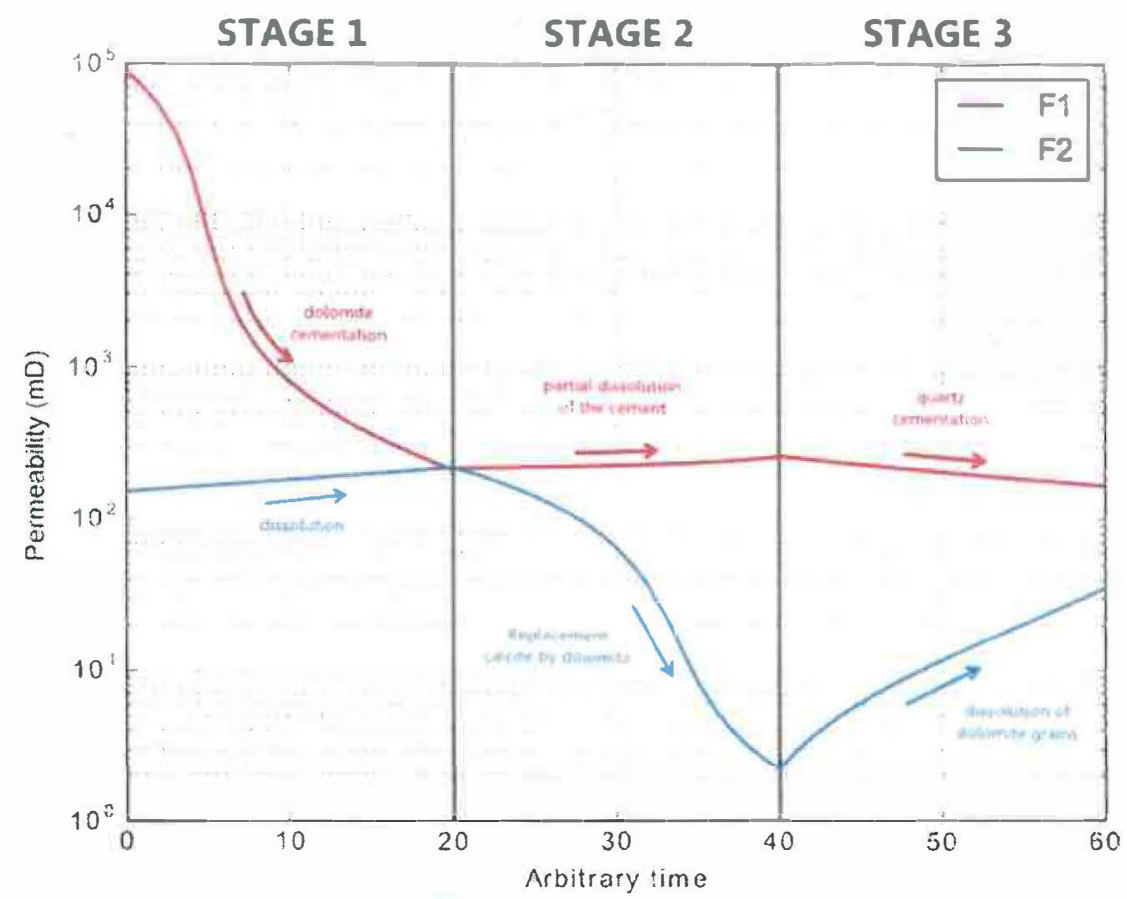

Figure 12. Extrapolation to permeability modeling using the same effective medium model evolution. 